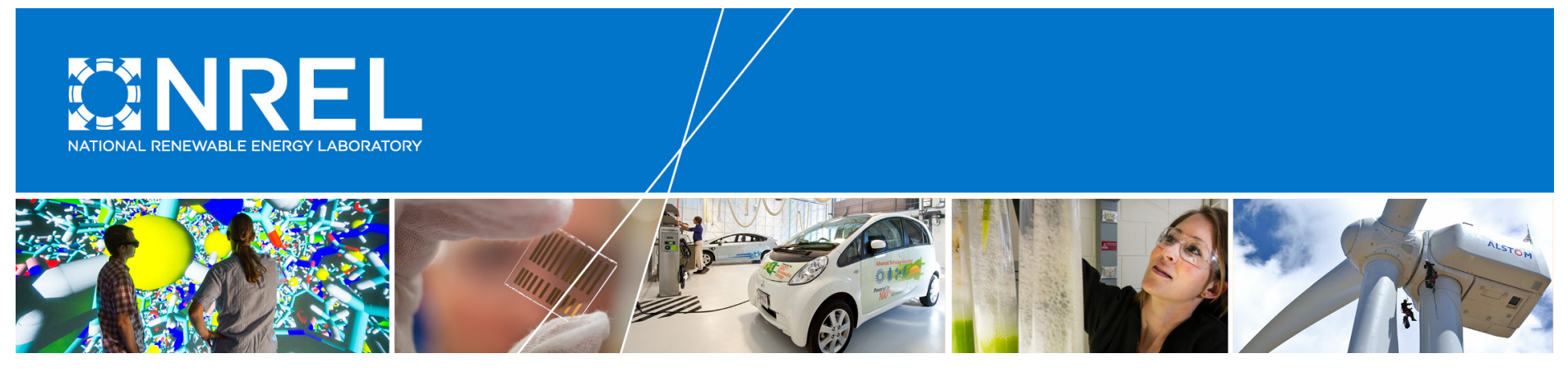

\title{
The Cost of Distribution System Upgrades to Accommodate Increasing Penetrations of Distributed Photovoltaic Systems on Real Feeders in the United States
}

Kelsey A. W. Horowitz, Fei Ding, Barry Mather, and Bryan Palmintier National Renewable Energy Laboratory

NREL is a national laboratory of the U.S. Department of Energy Office of Energy Efficiency \& Renewable Energy Operated by the Alliance for Sustainable Energy, LLC

This report is available at no cost from the National Renewable Energy Laboratory (NREL) at www.nrel.gov/publications.

Technical Report

NREL/TP-6A20-70710

April 2018 


\title{
The Cost of Distribution System Upgrades to Accommodate Increasing Penetrations of Distributed Photovoltaic Systems on Real Feeders in the United States
}

\author{
Kelsey A. W. Horowitz, Fei Ding, Barry Mather, \\ and Bryan Palmintier \\ National Renewable Energy Laboratory

\section{Suggested Citation} \\ Horowitz, Kelsey A. W., Fei Ding, Barry Mather, and Bryan Palmintier. 2018. \\ The Cost of Distribution System Upgrades to Accommodate Increasing \\ Penetrations of Distributed Photovoltaic Systems on Real Feeders in the \\ United States. Golden, CO: National Renewable Energy Laboratory. \\ NREL/TP-6A20-70710. https://www.nrel.gov/docs/fy18osti/70710.pdf.
}

NREL is a national laboratory of the U.S. Department of Energy Office of Energy Efficiency \& Renewable Energy Operated by the Alliance for Sustainable Energy, LLC

This report is available at no cost from the National Renewable Energy Laboratory (NREL) at www.nrel.gov/publications.

National Renewable Energy Laboratory 15013 Denver West Parkway Golden, CO 80401

303-275-3000 • www.nrel.gov

\section{Technical Report}

NREL/TP-6A20-70710

April 2018

Contract No. DE-AC36-08GO28308 


\title{
NOTICE
}

This report was prepared as an account of work sponsored by an agency of the United States government. Neither the United States government nor any agency thereof, nor any of their employees, makes any warranty, express or implied, or assumes any legal liability or responsibility for the accuracy, completeness, or usefulness of any information, apparatus, product, or process disclosed, or represents that its use would not infringe privately owned rights. Reference herein to any specific commercial product, process, or service by trade name, trademark, manufacturer, or otherwise does not necessarily constitute or imply its endorsement, recommendation, or favoring by the United States government or any agency thereof. The views and opinions of authors expressed herein do not necessarily state or reflect those of the United States government or any agency thereof.

This report is available at no cost from the National Renewable Energy Laboratory (NREL) at www.nrel.gov/publications.

Available electronically at SciTech Connect http:/www.osti.gov/scitech

Available for a processing fee to U.S. Department of Energy and its contractors, in paper, from:

\author{
U.S. Department of Energy \\ Office of Scientific and Technical Information \\ P.O. Box 62 \\ Oak Ridge, TN 37831-0062 \\ OSTI http://www.osti.gov \\ Phone: 865.576.8401 \\ Fax: 865.576.5728 \\ Email: reports@osti.gov
}

Available for sale to the public, in paper, from:

\author{
U.S. Department of Commerce \\ National Technical Information Service \\ 5301 Shawnee Road \\ Alexandria, VA 22312 \\ NTIS http://www.ntis.gov \\ Phone: 800.553 .6847 or 703.605 .6000 \\ Fax: 703.605.6900 \\ Email: orders@ntis.gov
}




\section{Acknowledgments}

The authors would like to acknowledge Jeremiah Miller and Robert Margolis for insightful discussions contributing to the development of this work. We would also like to acknowledge Alfred Hicks for his assistance with the graphics included in this report. This analysis was supported by the U.S. Department of Energy Office of Energy Efficiency and Renewable Energy Solar Energy Technologies Program [contract number DE-AC36-08GO28308]. The U.S.

Government retains and the publisher, by accepting the article for publication, acknowledges that the U.S. Government retains a nonexclusive, paid up, irrevocable, worldwide license to publish or reproduce the published form of this work, or allow others to do so, for U.S. Government purposes. 


\section{List of Acronyms}

ANSI

DC

DER

DPV

DRP

EPRI

IEEE

$\mathrm{kVA}$

$\mathrm{kW}$

MW

LCOE

LNBA

LTC

NREL

$\mathrm{PF}$

PV

Q

VAR

W
American Standard for Electric Power Systems and Equipment Direct current

Distributed energy resources

Distributed photovoltaic systems

Distributed resource plan

Electric Power Research Institute

Institute for Electrical and Electronics Engineers

kilo-volt-ampere (unit of apparent power)

Kilowatts

Megawatts

Levelized cost of energy

Locational Net Benefit Analysis

Load tap changer

National Renewable Energy Laboratory

Power factor

Photovoltaic

Reactive power

Volt ampere reactive

watts 


\section{Executive Summary}

The capacity of photovoltaic systems connected to the distribution system (distributed photovoltaic systems [DPV]) has increased consistently over the past 8 years in the United States, with continued growth anticipated globally. Because the power system was originally designed for one way power flow from centralized generators to distributed loads, this increasing deployment of DPV can impact operations at the distribution level and, for higher penetrations, at the transmission level. When these issues occur, upgrades are required to mitigate them and maintain voltage, reliability, and power quality, incurring a cost; we refer to these costs as distribution upgrade costs. While today these costs are typically analyzed reactively as individual DPV systems apply for interconnection to the grid, it is important to develop and implement forward-looking approaches for calculating distribution upgrade costs that can be used to inform system planning, market and tariff design, cost allocation, and other policymaking as penetration levels of DPV increase.

Using a bottom-up approach that involves iterative hosting capacity analysis, we calculate distribution upgrade costs as a function of DPV penetration on three real feeders - two in California and one in the Northeastern United States. For this initial report, we limit the set of mitigation strategies to traditional utility solutions and limited advanced inverter functionality (use of non-unity fixed power factor or local volt/VAR control). Additionally, we use the current prevailing practice for calculating hosting capacity and evaluating the potential impacts of DPV that is based on snapshot power flow analysis at minimum load and maximum photovoltaic (PV) output. This method does not capture time-varying behavior of loads, DPV systems, or voltage regulating devices on the feeder; additionally, it does not allow for assessment of the potential for DPV to defer distribution system upgrades. For these reasons, our results may overestimate costs required to maintain distribution system reliability, and reflect potential distribution system upgrade costs that could arise if utilities follow a "business-as-usual" approach, and additionally implement local advanced inverter functions consistent with upcoming changes to the IEEE 1547 standard for interconnecting distributed generation to the grid.

Key insights from this analysis include:

- There is significant variability in hosting capacity and distribution upgrade costs versus penetration level depending on the feeder, spatial distribution of DPV, and the size of the DPV systems. While we have selected a set of feeders and analysis scenarios intended to capture a range of representative cases, additional work is required to validate the extendability of our results to other systems.

- We find that DPV capacities between $6 \%$ and $88 \%$ of peak load could be integrated using advanced inverters plus traditional utility solutions with cumulative distribution upgrade costs ranging from $\$ 0$ up to $\$ 0.07 /$ rated DC watts ( $\mathrm{WDC}_{\mathrm{DC}}$ ). At the high end, these costs are equal to approximately $3.8 \%$ and $2.5 \%$ of total installed costs for commercial and residential PV systems in 2017. Higher penetration levels can be reached in some cases, at greater expense.

- In almost all scenarios on all feeders, the use of advanced inverters can significantly expand the hosting capacity at little or no cost. However, on two of the feeders, when the 
PV was clustered far from the substation, advanced inverters did not measurably increase the hosting capacity.

- Out of a set of fixed power factor (PF) options $(0.90,0.95,0.98,1)$ and volt/VAR control, the use of advanced inverters with fixed PFs of 0.95 (applied to all PV systems) resulted in the greatest expansion of the hosting capacity in all cases but one, where volt/VAR control was more effective.

- Distribution grid integration costs depend significantly on how DPV is spatially distributed, and costs could be minimized by guiding systems into low-cost or lowimpact locations. For two of the circuits we analyzed, PV clustered far from the substation resulted in considerably lower hosting capacities and higher costs than when PV was clustered near the substation or spread more evenly throughout the feeder. However, on one feeder, the initial hosting capacity was similar for all three of the spatial scenarios, and advanced inverters provided the greatest increase in hosting capacity for the case where PV was located far from the substation. This was because this particular feeder was short and heavily loaded, and had buses near the substation that were more susceptible to voltage violations.

- The hosting capacity on all feeders was initially limited by voltage constraints, most often overvoltage. In general, voltage violations were relatively low-cost to mitigate by using advanced inverters, and then adding line voltage regulators or capacitors and/or adjusting the set points of existing voltage regulating equipment. However, if a substation load tap changer (a voltage regulating device) is not already present and must be installed to mitigate violations, this can represent a substantial expense $(>\$ 300,000)$. Reconductoring was found to mitigate voltage violations in certain scenarios on one feeder, but at significant expensive, also potentially greater than $\$ 300,000$. The total cost of reconductoring depends on the amount of line that must be replaced as well as the size and type of line, which will vary by circuit.

- Upgrades to mitigate thermal overloads, including reconductoring or replacement of transformers, are generally expensive. For the feeders we analyzed, thermal constraints (in this case, overloaded secondary transformers) only limited the hosting capacity for one of them.

We considered three different spatial distributions of DPV for each feeder. These spatial distribution scenarios were selected to capture a wide range of potential costs-roughly speaking, worst, medium, and best cases - but are not based on PV adoption models and do not provide insights on the most likely outcome (models that can predict PV adoption at the household level, necessary to evaluate impacts at the feeder level, are still under development). A range of costs versus penetration for the three feeders analyzed in the "medium case" (where DPV are randomly distributed throughout the feeder) are shown in Figure ES-1. The cost ranges at each penetration level represent variability in the unit costs for different upgrades; however, because most available unit cost data come from a small subset of utilities in California and Northeastern United States, variability in unit costs across the United States is not fully captured. 


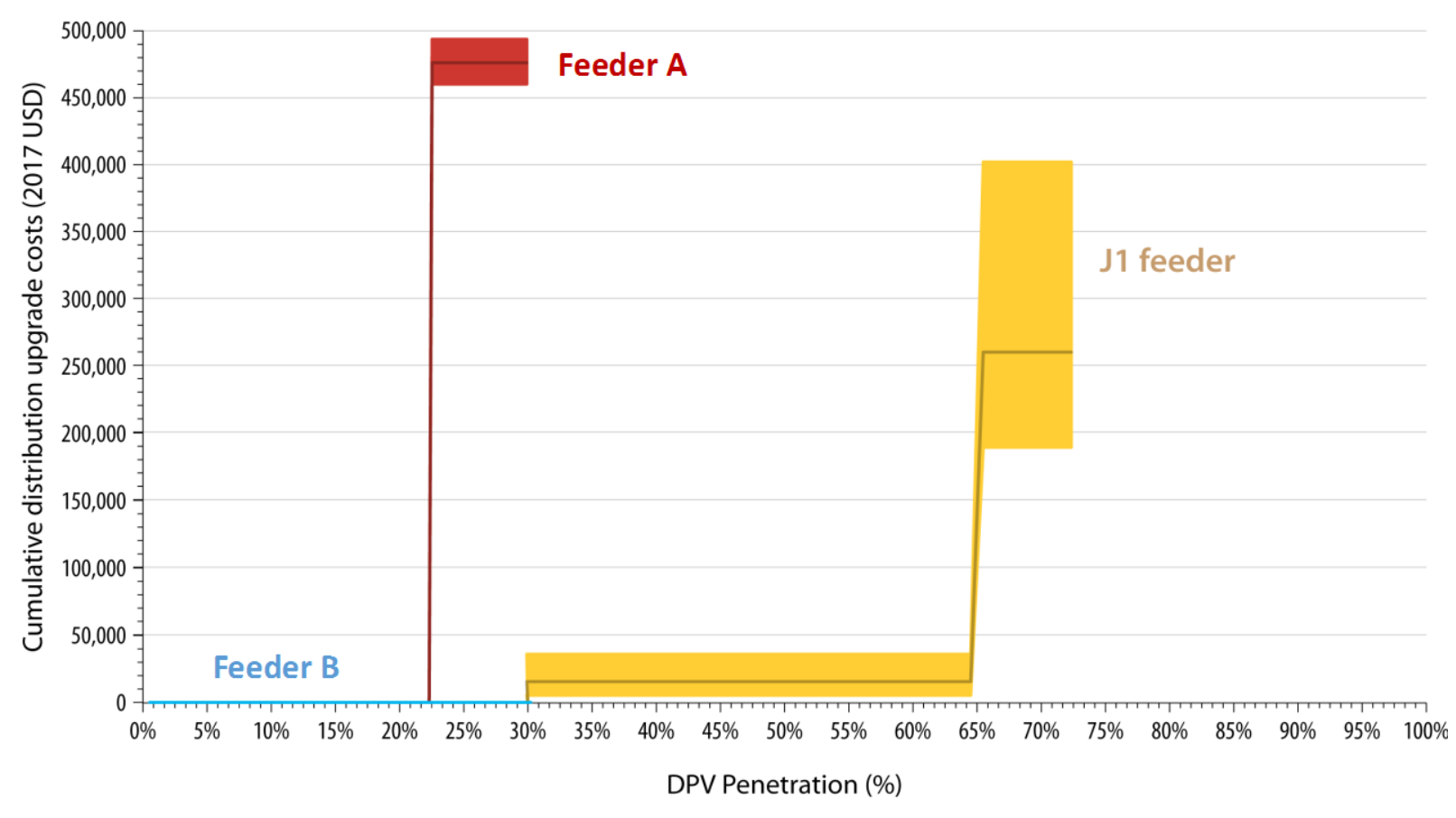

Figure ES-1. Range of distribution upgrade costs versus DPV penetration level (PV capacity/peak load) for the three feeders analyzed in the case where PV is randomly distributed throughout the feeder. The $\mathrm{J} 1$ feeder is located in the Northeast United States and is publicly available; the other two feeders (Feeder A and Feeder B) are real feeders in California. 


\section{Table of Contents}

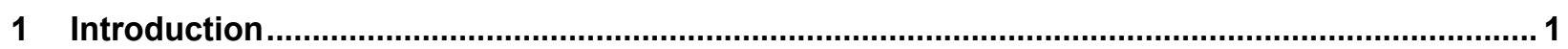

1.1 Terminology and Definitions of Distribution Upgrade Costs ................................................. 2

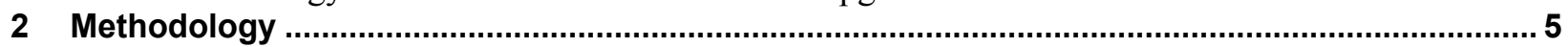

2.1 Hosting Capacity Analysis and Power Flow Modeling …...................................................... 7

2.2 Selecting Distribution Upgrades/Mitigation Strategies......................................................... 9

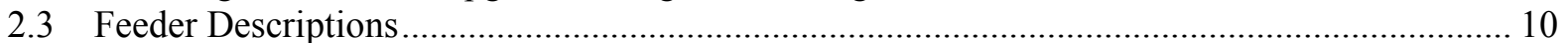

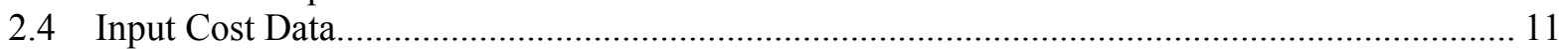

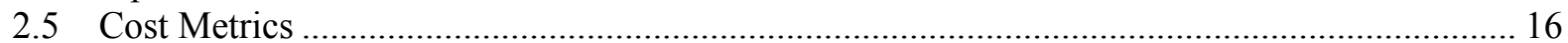

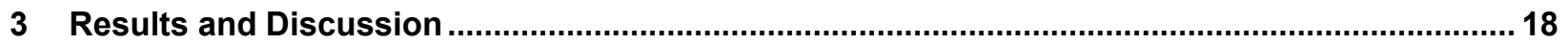

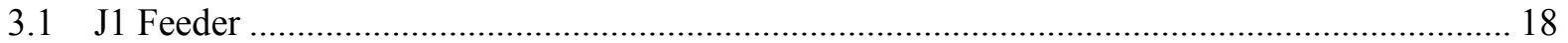

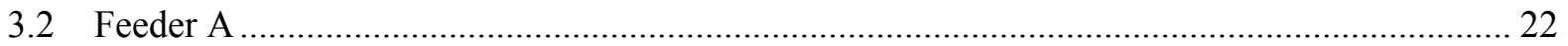

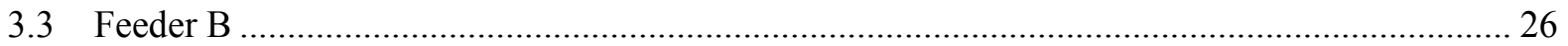

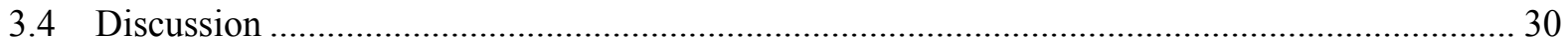

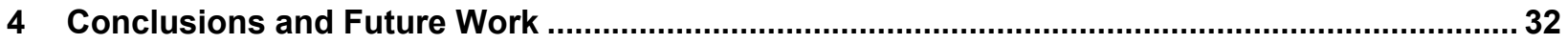

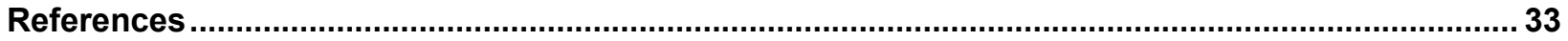




\section{List of Figures}

Figure 1. Diagram showing high-level components of grid integration cost-benefits 1

Figure 2. Relationship between different distribution grid integration cost terminology used in the literature and by different stakeholders. Overlapping shapes in the figure indicate there is some overlap in cost-benefits included under each of the shapes. For example, the cost of distribution system upgrades required to integrate DPV onto the grid are sometimes categorized as part of interconnection costs and grid modernization costs, in addition to upgrade costs (orange oval).

Figure 3. Diagram of the approach used to calculate distribution upgrade costs.................................... 5

Figure 4. Number (count) of PV systems with different sizes in $(\mathrm{kW})$ in each spatial DPV scenario for (a) the J1 feeder, (b) Feeder A, and (c) Feeder B. ..................................................................... 7

Figure 5. Volt/VAR curve considered in this analysis. $\mathrm{Q}$ is reactive power. pu $=$ per unit. .................... 10

Figure 6. Plot showing the curve fit to inverter price data used to estimate the premium associated with oversizing a residential PV inverter by $20 \%$.

Figure 7. Assumed low and high numbers of customers with PV, and corresponding advanced inverter cost premiums per watt in the case where inverters are oversized by $20 \%$ or a high cost premium is associated with the use of advanced inverters.

Figure 8. Cumulative distribution system upgrade cost versus penetration level on the $\mathrm{J} 1$ feeder for different spatial DPV deployment scenarios in the baseline case (no price premium for advanced inverters assumed); $\mathrm{HC}=$ hosting capacity....

Figure 9. Cumulative distribution system upgrade cost versus penetration level on the $\mathrm{J} 1$ feeder for different spatial DPV deployment scenarios in the high cost advanced inverter case (cost premium equal to that estimated for oversizing the rated inverter $\mathrm{kVA}$ by $20 \%$ ); $\mathrm{HC}=$ hosting capacity.....

Figure 10. Cumulative distribution system upgrade cost versus penetration level on the Feeder A for the three spatial DPV deployment scenarios in the baseline case (no price premium for advanced inverters). $\mathrm{HC}=$ hosting capacity.....

Figure 11. Cumulative distribution system upgrade cost versus penetration level on the Feeder A for the three spatial DPV deployment scenarios in the high advanced inverter case (cost premium equal to that estimated for oversizing the rated inverter $\mathrm{kVA}$ by $20 \%$ ). $\mathrm{HC}=$ hosting capacity. 25

Figure 12. Cumulative distribution system upgrade cost versus penetration level on Feeder $B$ for the baseline case (no price premium for advanced inverters). Only the close to the substation costs are shown because we found that only advanced inverters (which incur zero cost in the baseline case) were able to effectively increase the hosting capacity on this circuit for the random and far from the substation scenarios. $\mathrm{HC}=$ hosting capacity...............................2 28

Figure 13. Cumulative distribution system upgrade cost versus penetration level on Feeder $\mathrm{B}$ for the three spatial DPV scenarios for the high advanced inverter case (cost premium equal to that estimated for oversizing the rated inverter $\mathrm{kVA}$ by $20 \%$ ). $\mathrm{HC}=$ hosting capacity...... 


\section{List of Tables}

Table 1. Key Assumptions Used in the Hosting Capacity Analysis ...................................................... 9

Table 2. Characteristics of the Feeders Used in This Analysis .............................................................. 10

Table 3. Summary of Advanced Inverter Costs and Assumptions in Different Cases ............................. 12

Table 4. Summary of Upgrade Costs on the J1 Feeder ${ }^{\mathrm{a}}$........................................................................ 19

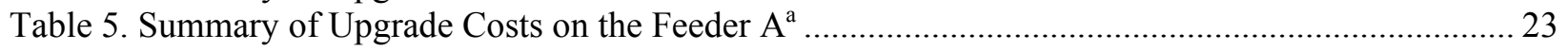

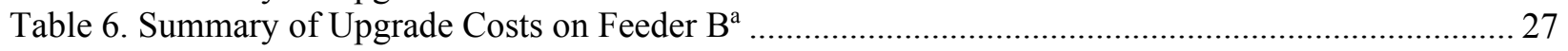

Table 7. Summary of Cumulative Costs (Mid Unit Cost Case) and Achievable Penetration Levels on Studied Three Feeders for the Baseline Case......................................................................... 31 


\section{Introduction}

Deployment of distributed photovoltaic systems (DPV) in the United States has increased consistently over the past 8 years, with continued growth anticipated globally (GTM and SEIA 2017, Cole 2017). While the overall contribution of DPV to electricity generation remains relatively low-less than $0.4 \%$ in the United States (EIA 2017, GTM and SEIA 2017) - several utilities have experienced very high local penetrations of DPV on some of their networks. For example, on Oahu, Hawaii distributed generation constitutes over $75 \%$ of peak load on certain circuits (HECO 2017). DPV penetrations can also increase rapidly-eight utilities located across the United States saw the amount of net metered PV installations on their systems increase tenfold between 2013 and 2016 (EIA 2017). In this landscape, it is critical to understand the potential impacts of DPV on the power system, and to develop and apply forward-looking approaches to calculating the costs and benefits of DPV that can be used to inform system planning, market design, and policymaking.

Grid integration cost-benefits associated with DPV (or any energy resource) include effects on the transmission system, distribution system, and generation at the bulk power system level (Figure 1). Distribution system upgrades are required when the installation of DPV causes operating conditions on the distribution network to deviate from acceptable bounds and mitigation measures must be implemented to ensure reliability, safety, and power quality. The penetration level at which upgrades would be required on a given feeder is termed hosting capacity. Conversely, DPV may allow for the avoidance of some upgrades, for example increasing the nameplate rating of transformers or distribution lines, by offsetting load growth. Whether the utility, PV developer, or system owner bears distribution upgrade costs or receives associated benefits will depend on the market structure and regulatory policy. Currently, for large DPV systems, PV developers typically incur costs associated with distribution system upgrades; for small, residential DPV systems, any upgrade costs and benefits typically accrue to the utility and are rate-based. While PV developers are not always compensated for any system benefits, on-peak capacity payments sometimes include generic transmission and distribution (T/D) capacity value.

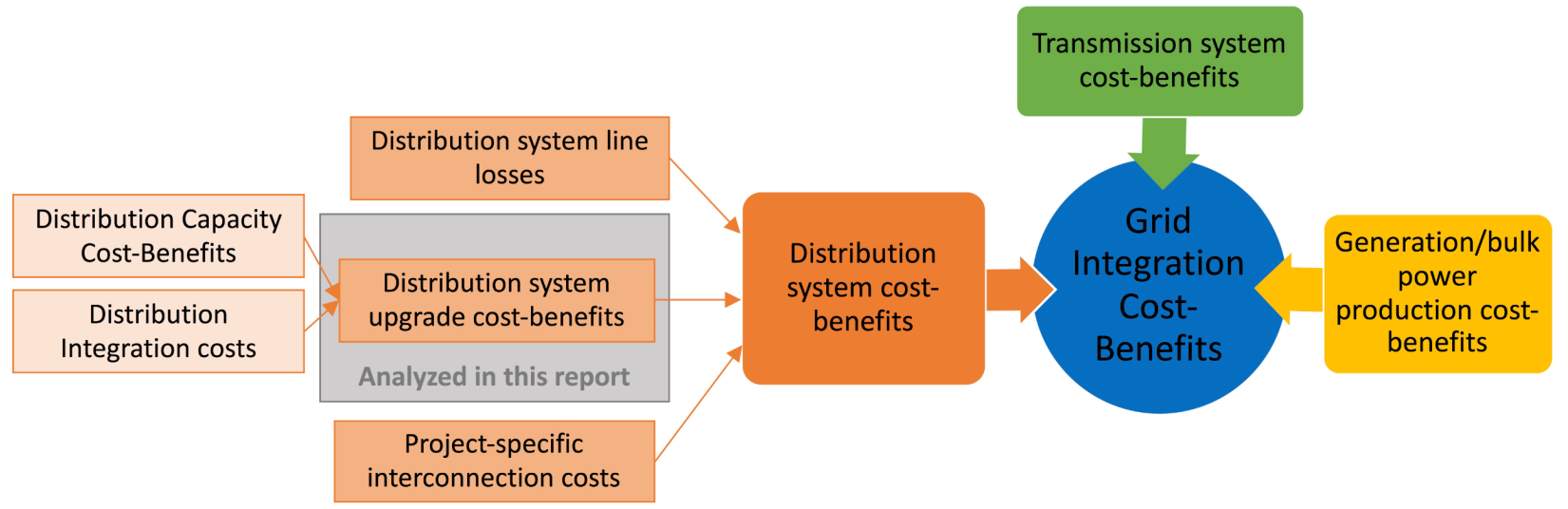

Note: Interconnection costs refer to the costs to physically and electrically connect individual systems to the grid, including the associated soft costs ("permitting, inspection, and interconnection" in (Fu 2017)). Interconnection costs do not include the cost any required distribution system upgrades, which are sometimes categorized as interconnection costs for larger DPV generators today. See discussion in Section 1.1 for more information.

Figure 1. Diagram showing high-level components of grid integration cost-benefits 
In this report, we assess distribution system upgrade cost-benefits, which we refer to as "net costs," as a function of the penetration level on three diverse feeders, assuming only simple, uncoordinated (local) advanced inverter functionality and traditional utility mitigation strategies are employed. Additionally, we use the current utility practice for determining the need for system upgrades that involves power flow modeling for a static, snapshot scenario with minimum load and PV production at its full-rated power. This work thus contributes to an understanding of what distribution upgrade capital costs could as a function of penetration level, up to very high penetration levels, in a "business-as-usual" case. The goal is to estimate the order of magnitude of distribution upgrade costs, assess key cost drivers, and identify sources of variability in costs depending on feeder characteristics and spatial distribution of DPV. We focus on the case where installed DPV capacity consists of small residential and commercial systems. We consider costs that might be incurred to either utilities, PV developers or system owners, or all ratepayers under current policy.

\subsection{Terminology and Definitions of Distribution Upgrade Costs}

Prior published analysis of distribution system costs associated with DPV and other distributed energy resources (DER) (Horowitz forthcoming) has revealed significant variability around terminology used to refer to different distribution costs and benefits in the literature.

Additionally, alternative terminology/definitions have emerged through working groups and regulatory proceedings related to DER integration, including the Locational Net Benefit Analysis (LNBA) working group in California (MTS 2016) and various distributed resource plan (DRP) documents. This section provides a clarification on the terminology used in this report, and how it relates to other definitions used by other authors and organizations. Further discussion on terminology and assumptions used in literature, as well as a discussion of how grid integration costs relate to the levelized cost of energy (LCOE) and other cost-benefits, is included in (Horowitz forthcoming).

- Cost versus Benefit-Terminology and Sign Conventions: In our analysis, we look at distribution system upgrade costs, including distribution capacity (lines and transformers) or other upgrades (e.g. voltage regulating equipment). Upgrade deferral benefits could not be assessed because we just conduct snapshot power flow analysis, and thus are not included in our results. Care should be taken when comparing these results to other work (and comparing other results to each other), which sometimes refers to cost as cost without netting out the benefits, or to benefits or value as benefits without netting out the cost; different categories of costs and benefits are often included in different analysis. Additionally, some analyses may include broader categories of value, including, for example, the value accrued to a PV system owner if the owners were to be compensated for ancillary services.

- Distribution Capacity Cost-Benefits: Terminology around distribution capacity is more consistent in the literature and larger community discussions, and typically refers to costs-and-benefits around incurring or deferring distribution line and transformer capacity increases due to overload. This is sometimes also referred to as "grid reinforcement." In this report, we do not include distribution capacity cost-benefits (see Section 2), but in general consider these costs to be a subset of net distribution system upgrade costs. Other authors have similarly included distribution capacity as a part of distribution upgrade costs, in some cases lumping capacity costs in with even broader 
definitions of distribution system costs that include line losses and/or opportunity costs for DPV (Stetz 2013), or have compared other system upgrades to increasing distribution capacity in their analysis (Stetz, Marten, and Braun 2013). Alternatively, some literature has used grid integration costs or benefits, infrastructure costs or benefits, or upgrade costs or benefits to refer exclusively to line capacity costs (Pudjianto 2013). Distribution capacity costs alone do not provide a comprehensive picture of costs that can be incurred on a distribution network when incorporating DPV.

- Interconnection Costs: Interconnection costs are costs associated with interconnecting specific DPV projects to the grid and include costs to connect a specific system physically and electrically as well as associated soft costs (e.g. "permitting, inspection, and interconnection" costs; Fu 2017). Currently, individual large DPV projects (typically 100 kilowatts $[\mathrm{kW}]$ to several megawatts $[\mathrm{MW}]$ ) are also responsible for any distribution system upgrades required to maintain power quality and reliability after a system is connected. The cost of any such required upgrades are categorized as interconnection costs in many Small Generation Inteconnection Procedure (SGIP) reviewed in Sena et al. 2014, and in at least one article on this topic (McConnell, 2017). It is of note that upgrade benefits (avoided upgrades) are not typically accounted for in interconnection impact studies, and developers are not currently compensated for any potential ability to defer upgrades. Understanding the ability of DPV projects to defer upgrades is complex, and relies on the resources providing power at the right time and place with the right availability and certainty for the utility. There is not yet a fully developed, agreed upon framework analyzing potential upgrade deferral benefits, though this is an active area of discussion and research.

- Alternative Names for Distribution Upgrade Costs: Several alternative names have been used for distribution upgrade costs in the literature, including distribution infrastructure costs, distribution integration costs (or grid integration costs), extra facilities costs (in an interconnection report), and distribution voltage and power quality costs.

- In particular, "distribution voltage and power quality costs" is the terminology adopted by the LNBA working group developing cost and value analysis methodologies for California (MTS 2016). While the assumptions and selection of upgrades to mitigate any impacts of DPV vary among published studies, as far as we can tell, these terms typically refer to the same general type of cost (with the exception of those studies that use infrastructure or integration costs to refer only to distribution capacity costs, as discussed previously).

- Grid Modernization Costs and "Fuzzy Costs": Grid modernization costs refer to overall system upgrades taken to modernize the grid and improve its operation, given the changing realities of the power system and the role of utilities and customers. 1 Grid modernization upgrades could include upgrades that ensure power quality and reliability are maintained as deployment of distributed energy resources in general (i.e. not just DPV) increases. It could also include upgrades meant to reduce outage times, increase resiliency, increase customer choice, replace aging infrastructure, or better utilize

\footnotetext{
${ }^{1}$ While this term is sometimes also used in reference to modernization efforts at the transmission and bulk power system level, we focus our discussion on grid modernization efforts related to the distribution system.
} 
distributed energy resources to avoid transmission system upgrades or the need to build additional of bulk power generators. The cost of grid modernization upgrades is "fuzzy" in that they often involve multiple motivations for adoption. While more DPV may be incorporated in a modernized grid, not all of these costs would be strictly required because of DPV alone. The grid modernization concept is relatively new, with concepts still being developed; the costs of such system-wide overhauls are not currently well known and (as with all distribution upgrade costs) will vary significantly by system, utility, and goals of different grid modernization efforts.

The relationship among the different terms used in the literature and public discussion are summarized below in Figure 2. This figure is intended to provide clarity on how the costs analyzed in this report-which we call distribution upgrade costs - relate to costs referenced in other reports, articles, and stakeholder discussions.

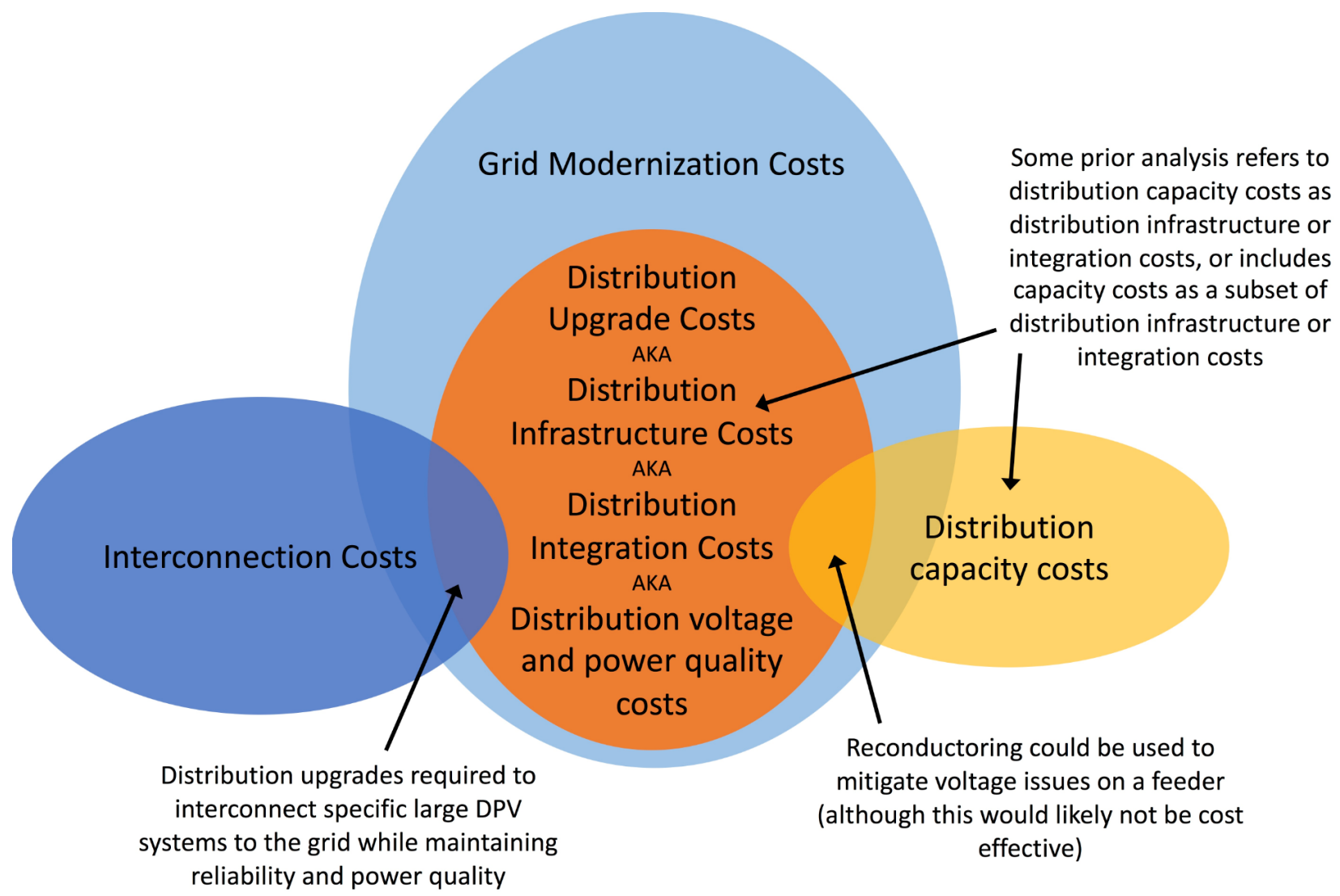

Note: Each cost refers to a net cost, inclusive of benefits. In the literature, sometimes costs are published without accounting for benefits, or, alternatively, a very broad set of potential benefits is included not strictly related to monetizable distribution grid benefits.

Figure 2. Relationship between different distribution grid integration cost terminology used in the literature and by different stakeholders. Overlapping shapes in the figure indicate there is some overlap in cost-benefits included under each of the shapes. For example, the cost of distribution system upgrades required to integrate DPV onto the grid are sometimes categorized as part of interconnection costs and grid modernization costs, in addition to upgrade costs (orange oval). 


\section{Methodology}

This analysis aims to capture a range of possible distribution upgrade costs as a function of DPV penetration and to identify key cost drivers. The general approach for calculating costs versus penetration on a given feeder is to conduct iterative hosting capacity analysis, wherein upgrades are sequentially deployed to mitigate any violations that occur and then the ability of those upgrades to expand the hosting capacity is assessed. Each mitigation strategy incurs an associated cost. This process is repeated until no additional DPV can be placed on the feeder without triggering a violation and there are no further options available that can successfully address the violation. This approach is outlined in Figure 3. The subsequent section describes the particulars of our analysis methodology. Further details of the methodology and assumptions used to perform power flow simulations and calculate hosting capacity are included in (Ding forthcoming). Our methodology aligns with current utility practice for hosting capacity, considering a static/snapshot, worst-case power flow scenario corresponding to minimum feeder load and output from the DPV systems at their rated power (EPRI 2012, Rylander et al. 2016, Seuss 2017, and Dubey 2017).

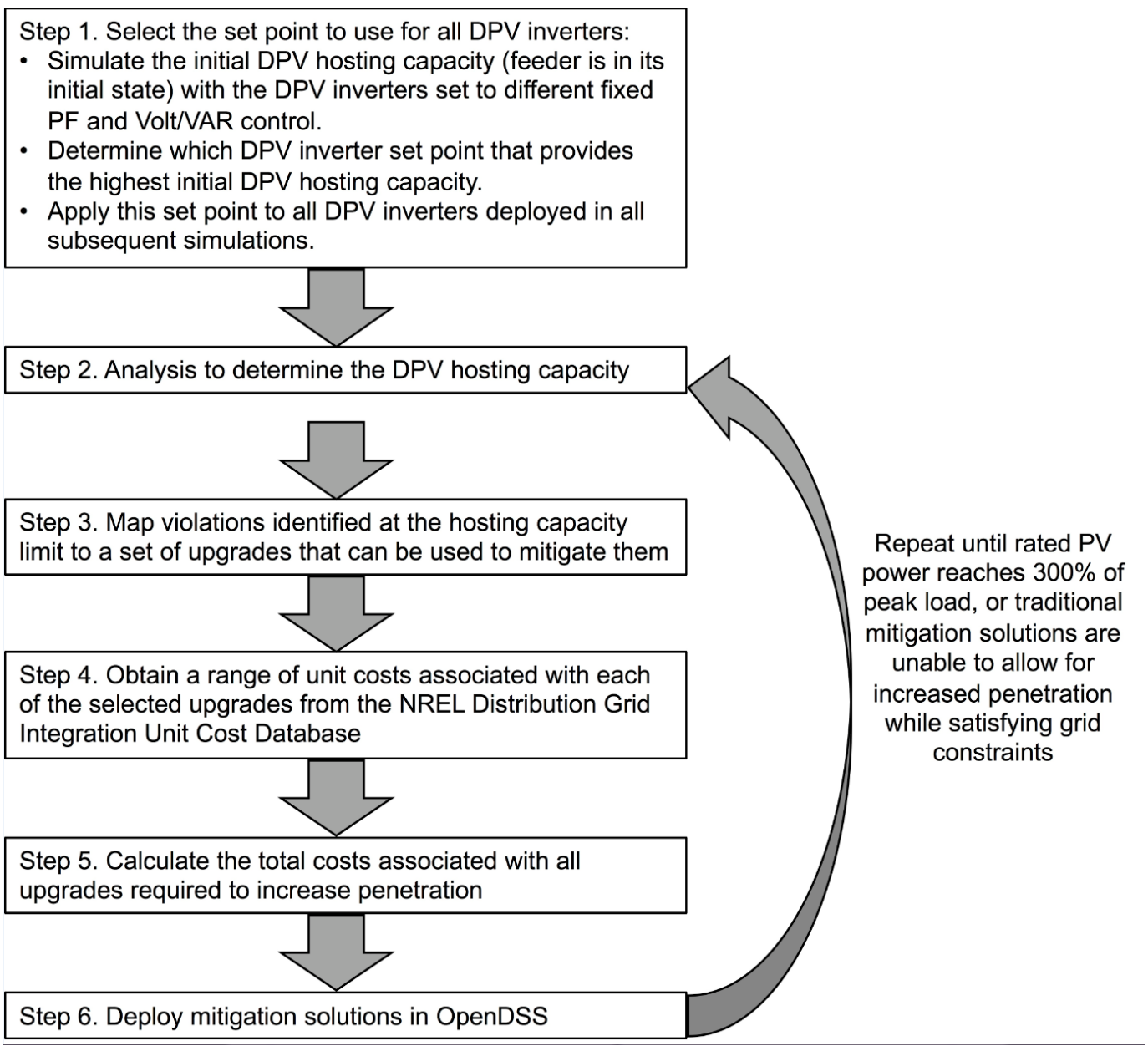

Figure 3. Diagram of the approach used to calculate distribution upgrade costs.

Distribution upgrade costs depend on what mitigation strategies are employed. We limit mitigation strategies to include (1) advanced inverters with either a fixed power factor (PF) or 
local Volt/VAR control, consistent with set points allowed in the forthcoming change to the IEEE 1547 standard, and (2) traditional utility solutions, for example, adding voltage regulators or modifying their set points, reconductoring, upgrading distribution transformers, etc. Emerging mitigation strategies, including advanced communications and controls schemes, battery energy storage, and distribution static synchronous compensators (D-STATCOM) are not considered in this analysis. Mitigation strategies used and how they were selected is described in more detail in Section 2.2.

In addition to which mitigation strategies are employed, upgrade costs vary depending on the characteristics of the feeder, location of DPV on the feeder, the size of DPV systems, and the unit cost for each mitigation strategy used. In this analysis, variability associated with each of these factors is captured as follows:

- Feeder characteristics - We calculate upgrade costs on three feeders: two in California (Feeders A and B) and one in the Northeastern United States (J1 feeder, a publicly available feeder from the Electric Power Research Institute [EPRI]), with diverse sets of characteristics. These feeders are described in more detail in Section 2.3.

- Spatial distribution of DPV - We consider a set of different spatial DPV deployment scenarios discussed in Section 2.1, as well as in (Ding forthcoming). These scenarios were selected to capture a wide range of potential system impacts, but do not identify the most likely outcome; the most likely deployment of DPV will vary by system and over time depending on the evolution of policies and electric rate designs. Validated, feederlevel DPV adoption models would be required to improve understanding of most-likely outcomes for a particular system.

- DPV system size - DPV consists of residential and commercial systems located near loads. The probability density functions for selecting system sizes were acquired from the California Solar Initiative's PV statistics data. These distributions were then sampled to determine the size of each PV unit. We then limit system sizes by assuming the PV system size cannot exceed the peak load value at the same bus. System sizes ranged from approximately $1 \mathrm{~kW}-500 \mathrm{~kW}$. Figure 4 shows the number (count) of PV systems of different sizes for each spatial scenario for each of the three feeders considered. At high penetrations, in the "far from the substation" and "close to the substation" scenarios, the PV systems are highly concentrated on certain buses, and thus their aggregate impact may be similar to installing single, larger systems. The approach for deploying and sizing $\mathrm{PV}$ is described in more detail in (Ding forthcoming).

- Some locations have experienced significant growth in residential and commercial PV in these size ranges. Others have seen more deployment of larger ground-mount systems, typically ranging between $500 \mathrm{~kW}$ to $10 \mathrm{MW}$. Additional analysis is required to assess potential variations in distribution upgrade costs when feeders are dominated instead by these large systems.

- Unit cost variations - We account for potential variations in the unit costs associated with different upgrades by including low, medium (mid), and high unit cost scenarios. Input data for these cases correspond to the minimum, average, and maximum unit cost values available in the National Renewable Energy Laboratory (NREL) Distribution Grid Integration Cost Database (NREL, 2017). While this approach captures some of the 
uncertainty associated with these costs, the available data tends to be from regions of the United States that have high penetrations of DPV (e.g. California, New York), which can also correspond to regions of relatively high cost. Input cost data is discussed further in Section 2.4 .

(a) J1 Feeder

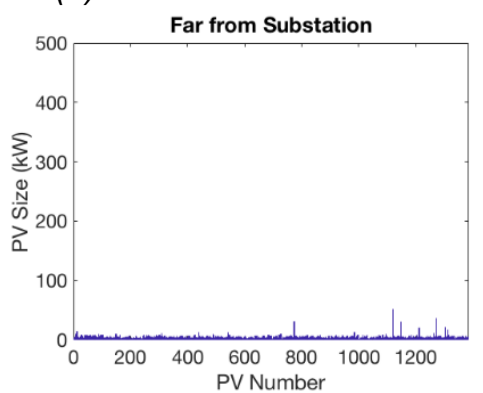

(b) Feeder $A$

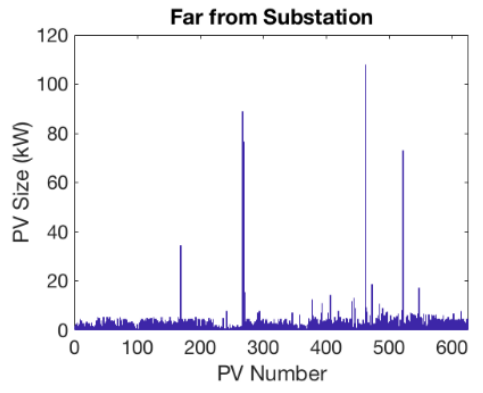

(c) Feeder B

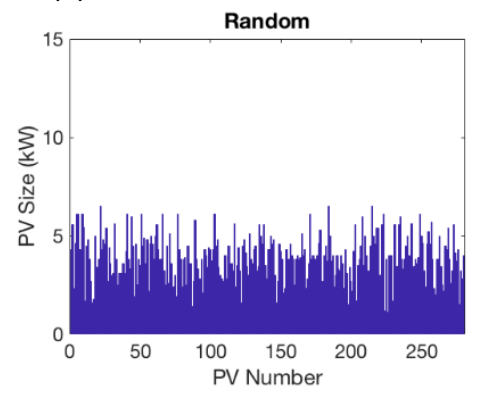

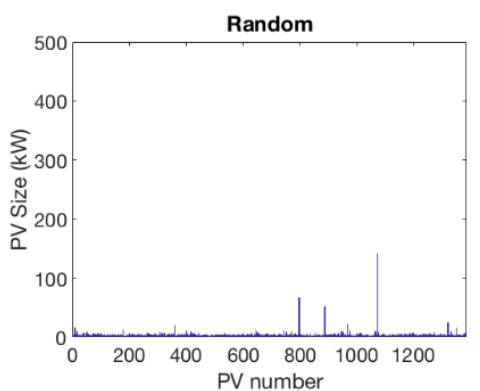
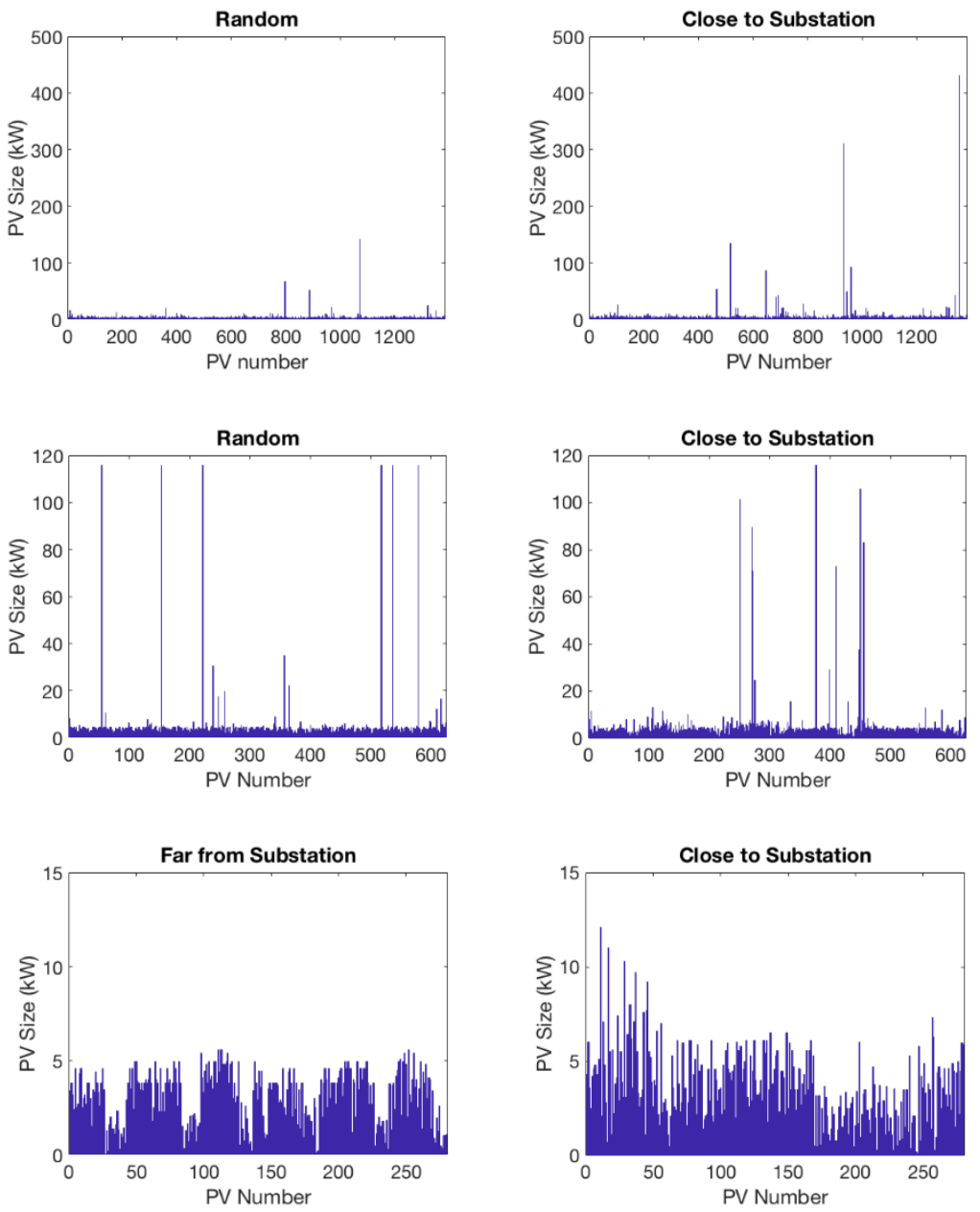

Figure 4. Number (count) of PV systems with different sizes in (kW) in each spatial DPV scenario for (a) the J1 feeder, (b) Feeder A, and (c) Feeder B.

To estimate net upgrades costs incurred by DPV, benefits should also be considered; in particular, the potential for DPV to defer distribution capacity upgrades ideally should be considered. The potential for such deferrals cannot be accurately assessed using the static/snapshot analyses used in this report, so the deferrals were not included in our analysis.

\subsection{Hosting Capacity Analysis and Power Flow Modeling}

We use hosting capacity analysis to assess the amount of PV that can be added to a specific feeder before triggering violations and requiring upgrades to be installed. As illustrated in Figure 3 , we then deploy selected upgrades in the feeder model, simulate the hosting capacity with the circuit in this new state, and iteratively perform this process until violations can no longer be mitigated using the allowed set of mitigation strategies. All hosting capacity analysis is 
performed using OpenDSS, EPRI's open source power system simulation tool (EPRI, n.d.). As discussed above, we use hosting capacity methodologies aligned with current utility practice as well as other research organizations (e.g., EPRI and Sandia) that consider static, snapshot, worstcase power flow scenario corresponding to minimum feeder load and output from the DPV systems at their rated power (EPRI 2012, Rylander et al. 2016, Seuss 2017, and Dubey 2017). Using this approach, time-varying voltage regulation behaviors of voltage regulators and capacitor banks that occur under normal operation in the field are not captured (their operation is "frozen" in our simulations, consistent with [EPRI 2012]). This means that the resulting hosting capacity may be conservative, because some voltage violations might be able to be mitigated effectively with existing voltage regulation equipment operating dynamically. It is of note that in this case voltage regulating equipment may operate more frequently than without DPV, causing potential increases in operations and maintenance $(\mathrm{O} \& \mathrm{M})$ that are not accounted for in our current analysis (Lave 2015).

We account for voltage violations (overvoltage, undervoltage, and voltage deviation) and thermal violations. Voltage deviation is a metric intended to capture the potential impacts of flicker that corresponds to as the voltage difference between the minimum load/zero or no PV scenario and the minimum load/nameplate PV production scenario. Protection limit is another vital metric to determine PV hosting capacity, but it requires detailed dynamic simulations to accurately analyze the impact of PV power on protection devices, which is out of the scope of this report. One prior study of the San Joaquin Valley region found that protection costs can be high on certain circuits (Navigant Consulting 2016); however, our interviews with utilities, as well as the data in the NREL Distribution Grid Integration Cost Database (NREL 2017) indicate that these costs vary significantly depending on the utility and specifics of their systems, and protection costs can be much lower than reported in the Navigant study.

As discussed above, hosting capcity depends strongly on both the location and size of DPV systems on the feeder. Prior analysis has indicated that voltage impacts tend to be worst when DPV is concentrated at the end of the feeder, least severe when the DPV is concentrated near the substation, and in-between when the DPV is spread more evenly throughout the system (Rylander, Smith, and Sunderman 2016, Ebe et al. 2016, Palmintier 2016). Thus, in order to capture a wide range of possible cost scenarios, we consider the following three cases of spatial DPV distributions on each feeder:

- Close to the substation-DPV has a much higher probability of being located close to the substation.

- Far from the substation-DPV has a much higher probability of being located at the end of the feeder, far from the substation.

- Random-DPV locations are randomly selected, resulting in a more even distribution of DPV throughout the feeder.

For each of these cases, we consider many different stochastic scenarios of DPV deployment, with the size of the PV systems varying between $1 \mathrm{~kW}$ and $500 \mathrm{~kW}$, as discussed above and shown in Figure 4. The algorithms used to generate each stochastic scenario are described in detail in (Ding forthcoming). Note that while we expect the use of these three spatial DPV distributions will capture a range of possible distribution upgrade costs that could be incurred, 
they do not provide a sense of the most likely outcome. Incorporating DPV adoption models into future simulations could provide a better sense of a range of costs that might be expected for a utility in a given area.

Key assumptions in our hosting capacity analysis are summarized in Table 1.

Table 1. Key Assumptions Used in the Hosting Capacity Analysis

\begin{tabular}{|c|c|c|c|c|c|}
\hline $\begin{array}{l}\text { Power Flow } \\
\text { Conditions }\end{array}$ & $\begin{array}{l}\text { Time } \\
\text { resolution }\end{array}$ & $\begin{array}{l}\text { Spatial } \\
\text { deployment } \\
\text { of DPV }\end{array}$ & $\begin{array}{l}\text { Size of } \\
\text { DPV } \\
\text { systems }\end{array}$ & $\begin{array}{l}\text { Violations } \\
\text { considered }\end{array}$ & $\begin{array}{l}\text { Effects not } \\
\text { considered }\end{array}$ \\
\hline $\begin{array}{l}\text { Minimum } \\
\text { load/name- } \\
\text { plate PV } \\
\text { production }\end{array}$ & $\begin{array}{l}\text { Static/snaps } \\
\text { hot analysis } \\
\text { used to } \\
\text { determine } \\
\text { hosting } \\
\text { capacity, } \\
\text { consisten } \\
\text { with current } \\
\text { utility } \\
\text { practice. }\end{array}$ & $\begin{array}{l}\text { Three cases } \\
\text { considered: } \\
\text { PV clustered } \\
\text { close to } \\
\text { substation } \\
\text { PV randomly } \\
\text { distributed } \\
\text { evenly } \\
\text { throughout the } \\
\text { feeder } \\
\text { PV clustered } \\
\text { far from the } \\
\text { substation }\end{array}$ & $\begin{array}{l}\text { Between } \\
1 \mathrm{~kW} \text { and } \\
500 \mathrm{~kW}\end{array}$ & $\begin{array}{l}\text { Overvoltage or } \\
\text { undervoltage: } \\
\text { Voltage outside of } \\
\text { ANSI limits } \\
\text { Overhead and } \\
\text { underground line } \\
\text { loadings within } \\
\text { limits } \\
\text { Transformer } \\
\text { loadings within } \\
\text { thermal limits } \\
\text { Voltage deviation: } \\
\leq 3 \%\end{array}$ & $\begin{array}{l}\text { Protection } \\
\text { impacts } \\
\text { Time-dependent } \\
\text { behavior of } \\
\text { voltage regulating } \\
\text { devices }\end{array}$ \\
\hline
\end{tabular}

\subsection{Selecting Distribution Upgrades/Mitigation Strategies}

In general, we limited the solutions used to mitigate DPV impacts to the types of upgrades that would be used in practice today (i.e., traditional utility solutions). This establishes a baseline aligned with prevailing utility practice that can be compared to results obtained using other solutions in future work. Indeed, higher penetration levels and/or lower upgrade costs might be achieved in the using advanced integration solutions (e.g. dynamic DPV curtailment, thermal load shifting, D-STATCOM, etc.) not explored here.

For all cases, we first used very basic advanced inverter functionality to attempt to mitigate voltage violations, as outlined in Step 1 of Figure 3. This is because advanced inverters represent a relatively low-cost option to expand the amount of DPV that could be incorporated on each feeder beyond the initial hosting capacity. The advanced inverter settings considered here include: (1) changing to a fixed, non-unity PF and (2) volt/VAR control. These settings were selected to align with the first phase of upcoming revisions to the IEEE 1547 standard and operating standards under California's Rule 21 recommended by the Smart Inverter Working Group (SIWG). Some utilities have also already started to experiment with non-unity PFs and volt/VAR control for PV inverters in select projects or pilot programs. These are both local approaches that do not require any communication or coordination with other devices or entities. For each case, we ran power flow simulations with fixed PF of 0.95, 0.98, and 1 as well as with a volt/VAR setting (Figure 5). 


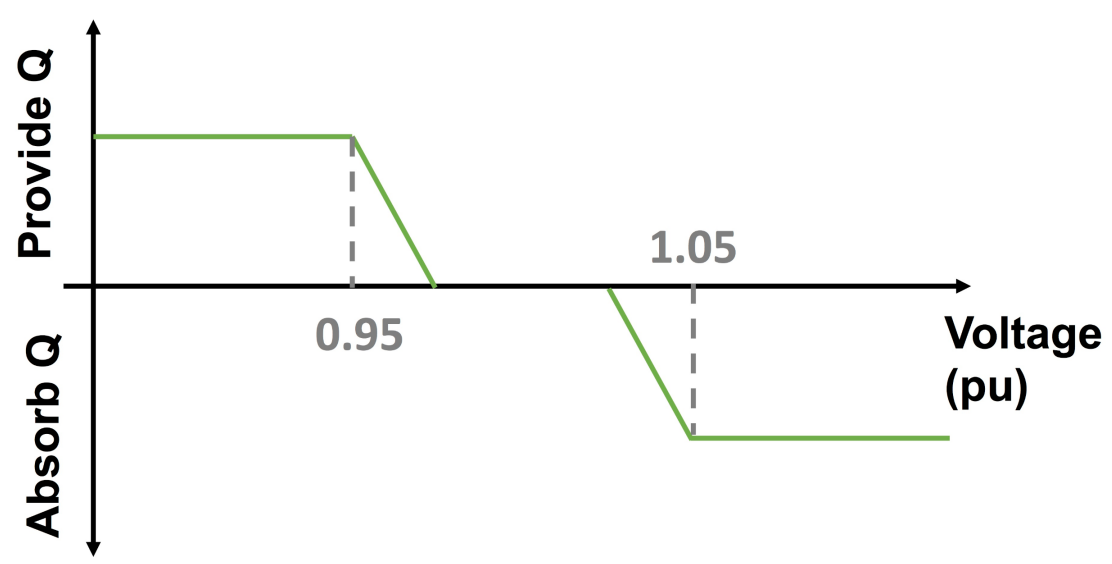

Figure 5. Volt/VAR curve considered in this analysis. $Q$ is reactive power. pu $=$ per unit.

After advanced inverters, we selected upgrades manually using engineering expertise on what solutions might prove most effective at the lowest costs. This process involves examining where the violations are occurring on the feeder, deploying the lowest unit cost solutions (as determined from the NREL Distribution Grid Integration Cost Database) that have been shown to effectively mitigate the violation in practice (Seguin 2016), simulating their effect on hosting capacity, and, if they prove ineffective at expanding hosting capacity significantly, considering other options. The applicability of different possible upgrades varied by feeder. However, in general, for voltage violations, we started by trying to adjust the set points on the existing capacitor banks and voltage regulators, and if that was not effective, added additional capacitor banks and voltage regulators. If these approaches were unsuccessful, we considered reconductoring the line, although this was never found to be an economical solution to mitigating voltage violations and is unlikely in practice. For thermal violations, selecting solutions was more straightforward-we increased the rating of the overloaded lines or transformers to the next standard size until the violation was mitigated.

We did not consider all possible upgrade options and do not claim the upgrades selected here are optimal; i.e., lowest cost. In fact, what is lowest cost depends on what penetration levels are being considered (Horowitz forthcoming).

\subsection{Feeder Descriptions}

Table 2 summarizes the characteristics of the three feeders analyzed in this study (J1 feeder, Feeder A, and Feeder B). The J1 feeder is located in the Northeastern United States, and the feeder data is publicly available from EPRI. ${ }^{2}$ The other two (Feeder A and Feeder B) are real feeders located in California, a subset of 17 feeders previously selected from hundreds of California feeders to caputure representative feeder characteristics (Ding 2017). We selected feeders that have a diverse set of characteristics (summarized in Table 1) to capture the drivers of distribution upgrade costs in a range of different scenarios. Our analysis was limited to three feeders due to the scope of this project and availability of feeder data.

Table 2. Characteristics of the Feeders Used in This Analysis

\begin{tabular}{lrcc}
\hline Parameter & J1 Feeder & Feeder A & Feeder B \\
\hline Primary voltage $(\mathrm{kV})$ & 12 & 12.47 & 4.16 \\
\hline
\end{tabular}

2 “Feeder J1,” Distributed PV Monitoring and Feeder Analysis, EPRI, http://dpv.epri.com/feeder j.html 


\begin{tabular}{lrrr}
\hline Parameter & J1 Feeder & Feeder A & Feeder B \\
\hline Maximum load (MW) & $5.95^{\mathrm{a}}$ & 7.65 & 1.99 \\
Customers & 1384 & 625 & 250 \\
$\quad$ Residential & 1354 & 291 & 220 \\
$\quad$ Commercial & 30 & 334 & 30 \\
Maximum distance from & & 9.7 & 2.36 \\
substation to feeder node & 18.08 & & \\
(kilometers) & & 5.71 & 2.386 \\
Maximum X/R of primary bus & 9.724 & 0.669 & 0.7175 \\
Minimum X/R of primary bus & 1.206 & 2.206 & 1.179 \\
Average primary X/R & 2.811 & 6 & 2 \\
Capacitor count & 5 & 4800 & 600 \\
Capacitor total kVAR & 3900 & 0 & 0 \\
Line regulator count & $8^{\mathrm{b}}$ & 0 & 1 \\
Substation load tap changer & 1 & & \\
(LTC) count & & & \\
\hline
\end{tabular}

a There is another $5 \mathrm{MW}$ load directly connected at the secondary side of the substation transformer.

${ }^{\mathrm{b}}$ Eight single-phase regulators exist on the $\mathrm{J} 1$ feeder.

\subsection{Input Cost Data}

All input cost data, except for advanced inverter costs (discussed below), was drawn from the NREL Distribution Grid Integration Unit Cost Database that contains data from a variety of different sources including utilities, developers, engineering consultants, and technology vendors (NREL n.d.). We attempted to create low, mid, and high cost scenarios based on the minimum, average, and maximum unit costs for each component from the database. However, some components only had one data point; in this case, the one data point was used for the low, mid, and high scenarios (details on what costs were assumed for each scenario on each feeder are specified in Section 3. Even where multiple data points were available in the database, the cost ranges do not necessarily reflect the full range of costs that might be observed in practice. For example, much of the data comes from California utilities, that have published unit cost guides as required under California Rule 21 (California Public Utilities Commission 2018), but California tends to have higher costs (labor, sales tax, etc.) compared to the rest of the country, and thus cost estimates may be skewed high compared to what would be expected for a national average. Thus, we do not claim the results included here capture the full range of possible upgrade unit costs. In practice, unit costs for different upgrades will vary by utility and location, and the purpose of this analysis is not to estimate a specific utility's potential costs, but rather to better understand the order of magnitude of possible distribution upgrade costs, identify major cost drivers, and introduce a method of forward-looking cost analysis that considers potential upgrade needs as a function of penetration and at high penetration levels, rather than as reactive upgrades to enable interconnection of specific DPV systems. Additionally, the significant variability observed between feeders in terms of what and how many upgrades are required at different penetration levels will likely exceed the variability in unit costs between utilities. 


\section{Advanced Inverter Costs}

There are two possible cost increases associated with the advanced inverters compared to traditional inverters:

1. The marginal cost of an inverter that is capable (from a hardware and firmware perspective) of providing the required advanced functionality

2. The marginal cost of oversizing an inverter so that it can provide reactive power to regulate voltage without curtailing the real power output from the DPV array, thus incurring an opportunity cost to the DPV system owner

We explored the potential cost associated with each of these factors and included two cases in our analysis: a baseline advanced inverter cost case and a high advanced inverter cost case. Table 3 summarizes these different cost cases. Note that any potential cost premiums, due either to purchasing an inverter with more advanced features or oversizing an inverter, would currently be born by the DPV system owner and not the utility. However, there have been some pilot programs in which the utility pays for and owns DPV systems in order to control the output and leverage advanced inverter features for system support (Adhikari 2015).

The remainder of this section describes how we selected the values used in the baseline and high advanced inverter cost scenarios (Table 3 ).

Table 3. Summary of Advanced Inverter Costs and Assumptions in Different Cases

\begin{tabular}{|c|c|c|c|}
\hline Case & $\begin{array}{l}\text { Assumed } \\
\text { Modifications } \\
\text { Required }\end{array}$ & $\begin{array}{l}\text { Assumed Price } \\
\text { Premium (2017 } \\
\text { \$/inverter) }\end{array}$ & Use in Our Analysis \\
\hline \multicolumn{4}{|l|}{ Newly installed inverter } \\
\hline - Not oversized & & $\$ 0$ & Used in all baseline scenarios \\
\hline - Oversized by $20 \%$ & & $\$ 143$ & $\begin{array}{l}\text { Used in oversized inverter/high inverter } \\
\text { cost scenario }\end{array}$ \\
\hline $\begin{array}{l}\text { Inverter installed } \\
\text { between } 2012 \text { and } 2017\end{array}$ & $\begin{array}{l}\text { Setting update: } \\
\text { remote or with } \\
\text { truck roll }\end{array}$ & $\$ 0-\$ 150$ & $\begin{array}{l}\$ 143 \text { used in the oversized } \\
\text { inverter/high inverter cost scenario }\end{array}$ \\
\hline $\begin{array}{l}\text { Older inverter (already } \\
\text { installed) without } \\
\text { technical capability to } \\
\text { provide advanced } \\
\text { functionality }\end{array}$ & Full retrofit & $\leq \$ 703$ & $\begin{array}{l}\text { Not used - prohibitively expensive, } \\
\text { would not be used in practice. } \$ 703 \text { is } \\
\text { a high estimate based on the German } \\
\text { retrofits of } 2012 \text {. Additionally, older } \\
\text { inverters will likely be replaced with } \\
\text { newer ones capable of advanced } \\
\text { inverter functionalities at their end-of- } \\
\text { life. Advanced features could be } \\
\text { enabled at install at no additional cost. }\end{array}$ \\
\hline
\end{tabular}

In 2016 and 2017, we interviewed two leading inverter manufacturers about the two potential cost increases mentioned previously. ${ }^{3}$ With respect to point 1 , both companies said that their inverters currently have the ability to operate at an alternative fixed PF or use volt/VAR control,

\footnotetext{
${ }^{3}$ The names of the manufactures are omitted to protect business sensitive information
} 
and that, at most, a firmware update and/or a setting change would be required to enable these functionalities.

For new DPV systems, this can be done during installation with no real marginal cost increase. For systems that were already installed with the required hardware to provide advanced functionality, this setting change or firmware update might be performed remotely or, in some cases, could require a professional to visit the PV site ("a truck roll") to manually adjust settings, which would likely be a couple hundred dollars at most. Both manufacturers also noted, when asked about potential price increases for inverters with more advanced features compared with older versions of the inverter, that the market continually demands more features at lower prices, so the marginal price increase associated with adding advanced features is zero or small and difficult to allocate. Similarly, in 2013 Marshall Bates, then vice president of the Medium Power Solutions at SMA America, said in an interview with Greentech Media that, outside of the case where the grid operator requires a separate communication channel, the cost premium for an advanced inverter "could likely be eliminated altogether". ${ }^{4}$ A separate communication channel is not required to implement the local voltage regulation functionalities assumed in this report.

Most inverters on the market today - and that have been on the market for the last several years, at least back to 2012 or 2013 - are technically capable of providing advanced functionality if "activated" as previously described, but are often prevented from doing so because of prevailing standards and regulations; however, these standards and regulations are now starting to evolve.

Much older inverters on PV systems installed before 2012 or 2013 may require retrofits to provide certain advanced functionality. In Germany, DPV penetrations increased rapidly to very high levels due to generous feed-in tariffs and decreasing system prices, leading to concerns about stability of the power system. In response, in 2012 regulators required approximately 315,000 PV system inverters be retrofit to enable advanced features; in particular frequency ridethrough capability. ${ }^{5}$ It was reported that the sum of these retrofits cost 175 million $€$, equivalent to approximately $\$ 221$ million (2017) or \$703/inverter, exceeding the entire cost of a standard inverter at the time (von Appen 2013). This cost is prohibitively expensive in many cases, and indeed our subsequent interviews with utilities and solar developers indicate that similarly extensive retrofits of older, previously deployed inverters that do not have the technical capability to provide advanced features are not even considered due to anticipated high cost. This means that in scenarios where a significant fraction of DPV systems were deployed prior to around 2012, or where a substantial fraction of DPV systems were deployed prior to 2012 at key locations on the feeder for providing voltage support (even if most systems on the feeder are new, deployed after 2012), inverters may not be able to expand the network's hosting capacity to the degree shown in this report without incurring significant (and prohibitive) retrofitting costs. Future work to explore the sensitivity of the distribution upgrade costs to the fraction of inverters capable of providing advanced functionality would be beneficial for utilities that had high penetrations of DPV prior to 2011 or 2012 (e.g., California). The market might also decide to

\footnotetext{
4 "SMA: PV Inverters Can Be Made Grid-Smart for Little Additional Cost," Greentech Media, October 17, 2013 , https://www.greentechmedia.com/articles/read/SMA-Sees-Little-Costs-to-Make-Inverter-Grid-Smart\#gs.hBrYDtY

5 “Retrofit of PV Plants in Germany for 50.2 Hz Issue," Delta Electronics, June 18, 2014, http://www.solarinverter.com/en-GB/797.htm
} 
just wait until these inverters need to be replaced, since many of the inverters installed around 2012 are expected to last for approximately 10 years (SunShot 2012).

In addition to any premiums associated with enabling advanced inverter features, there may also be a premium associated with oversizing the inverter enough so that reactive power can be provided without reducing real power output. When an inverter is operating at its maximum or rated real power point, reactive power cannot be provided without reducing real power output, resulting in an opportunity cost for the PV system owner. Thus, the inverter apparent power (kVA) rating may be increased to allow for reactive power support without incurring this opportunity cost; in our power flow simulations, we conservatively oversized the inverters by $20 \%$ (beyond what would be selected in a scenario where no reactive power is provided). In reality, inverters would likely not need to be oversized to this degree, or may not need to be oversized at all, to avoid real power curtailment because, depending on the location, PV systems often produce well below their rated power. Because of this, we do not include the oversizing cost premium in our baseline scenario (indicative of a more likely or more typical scenario) for analysis. ${ }^{6}$ Instead, we explore the potential impact of oversizing the inverter by $20 \%$ in a series of high-inverter cost scenarios. In these cases, we apply the premium to all inverters on the system; i.e., assume that all systems are newly installed and that inverters can be oversized only at the time of install. In a region where a large of number of DPV systems are already installed, the assumption is that some real power reduction may be required (again, depending on the solar resource and typical real power output compared to the rated power).

The cost of oversizing by $20 \%$ was very roughly estimated by fitting data for residential $(5.7 \mathrm{~kW})$, commercial $(200 \mathrm{~kW})$, and utility-scale $(100 \mathrm{MW})$ inverter costs per watt from $(\mathrm{Fu}$ 2017), as shown in Figure 6. Using this approach, we estimate a premium of approximately $\$ 143$ inverter for oversizing a $5.7 \mathrm{~kW}$ residential inverter by $20 \%$. This premium also captures the very high end of previous estimates for price premiums to purchase inverters with advanced functions ${ }^{7}$ and thus gives a conservative number for a high inverter cost case in general.

\footnotetext{
${ }^{6}$ Note that inverters may be oversized for other system design reasons. Throughout this report, anytime we are referring to oversized inverters, we are referring to an increase in size beyond the baseline size assumed for that system type that is intended to allow for reactive power provision without having to reduce real power output. ${ }^{7}$ In 2013, the Western Electric Industry Leaders industry group published a white paper estimating that up to around $\$ 150$ /inverter might be added to the manufacturing cost in order to enable advanced features, equal to roughly $10 \%$ of the inverter price at the time (Western Electric Industry Leaders 2013). This premium assumed the addition of a host of advanced inverter functions beyond just basic PF changes, including frequency ride through and antiislanding capabilities. The price of inverters has come down significantly, and $10 \%$ of the price of a $5.7 \mathrm{~kW}$ residential inverter in the United States is now equal to approximately \$74/inverter. We still view this valuation as an overestimate of the price premium based on our interviews with inverter companies and increasing experience with advanced inverter manufacturing, but this value is captured within the range of possible costs explored in our analysis.
} 


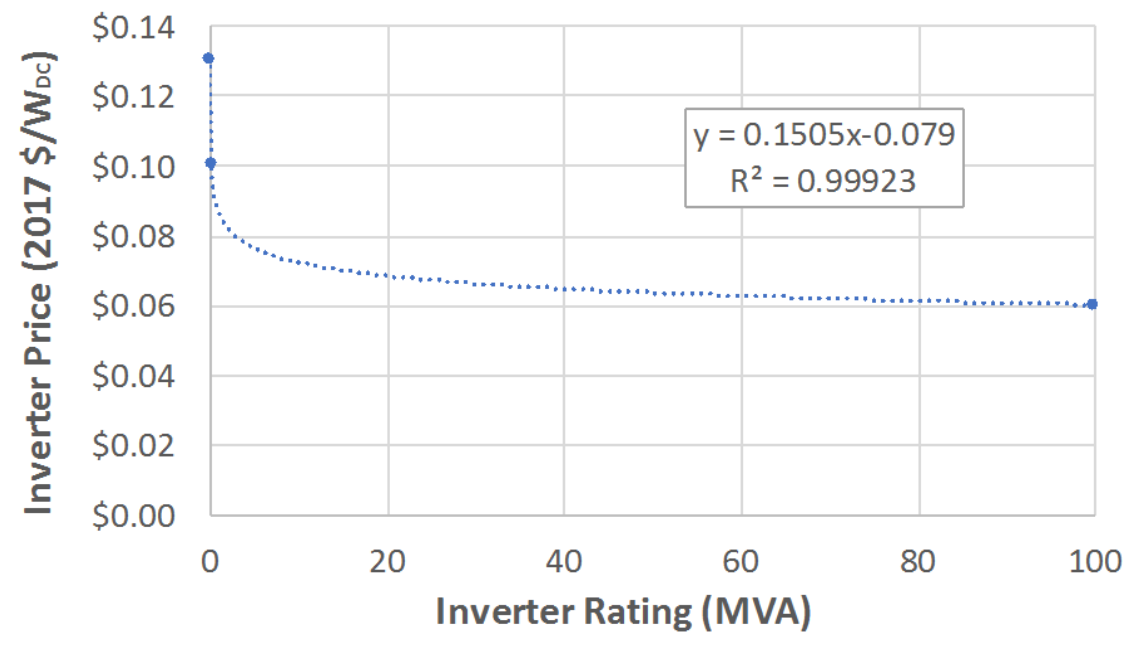

Figure 6. Plot showing the curve fit to inverter price data used to estimate the premium associated with oversizing a residential PV inverter by $20 \%$.

To estimate costs when the potential cost premium of oversizing the inverters by $20 \%$ is considered, we obtained a low, mid, and high customer count versus penetration based on the stochastic scenarios used for the power flow simulations. We assumed the same customer counts versus penetration level for all three spatial scenarios. The advanced inverter cost premium at each penetration level was then set equal to the customer cost at that penetration level multiplied by $\$ 143$. Cost per watt was calculated by dividing the total cost per feeder by the sum of the rated power for all DPV systems installed on the feeder. The resulting costs are illustrated in Figure 7. Because our simulations assume all inverters are set to have the same new settings (a non-unity PF or volt/VAR control), this cost is immediately incurred rather than once the hosting capacity is reached. 


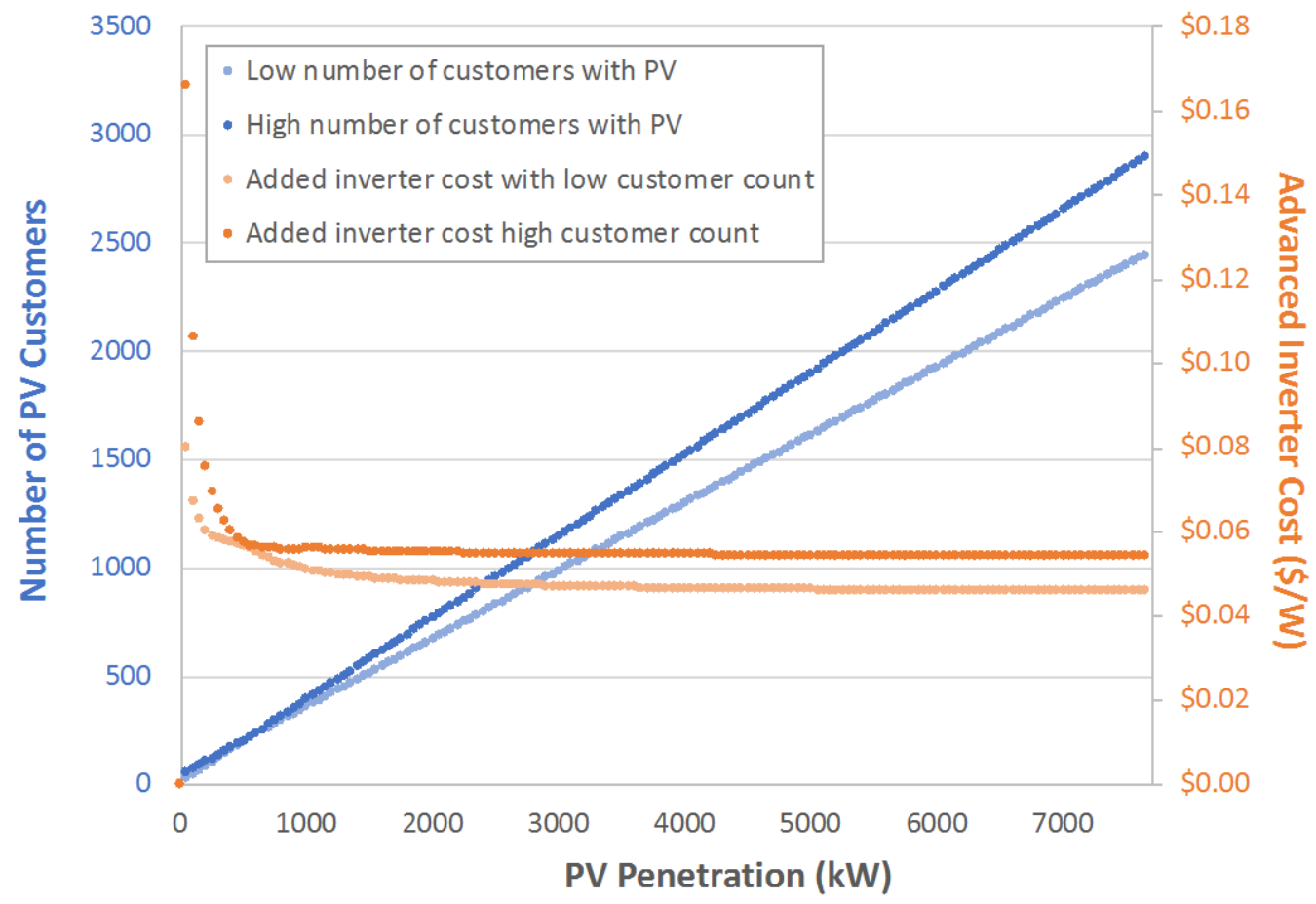

Figure 7. Assumed low and high numbers of customers with PV, and corresponding advanced inverter cost premiums per watt in the case where inverters are oversized by $20 \%$ or a high cost premium is associated with the use of advanced inverters

\subsection{Cost Metrics}

Three cost metrics are calculated and discussed in this report:

1. Cumulative distribution system upgrade costs - cumulative costs associated with all upgrades plotted as a function of penetration level.

2. The average cost per watt of all distribution system upgrade costs-This cost is calculated as the cumulative costs on a given feeder up to the maximum penetration level, divided by the total rated (DC) watts of all PV on that feeder at the maximum penetration level.

3. The marginal cost per watt associated with a particular upgrade - This is the cost of the upgrade divided by the marginal increase in the PV hosting capacity (in DC rated watts) enabled by the implementation of that upgrade.

Dividing the total cost by PV rated watts allows for an easier comparison to the total installed system cost of PV generators, and is useful for understanding whether the upgrades would be economically feasible under different cost allocation schemes. These metrics could also be useful in developing fair schemes to allocate costs among PV generators. Additionally, the marginal cost per watt associated with a particular upgrade provides a measure of the upgrade's effectiveness compared to its cost. 
Similarly, we define the average cost per watt for advanced inverters across penetrations as:

$$
C_{i n v, \text { avg }}=\frac{N_{P V}\left(p_{\max }\right) \cdot P_{i n v}}{p_{\max }}
$$

where:

- $p_{\max }$ is the maximum penetration level that achieved for a given scenario, in $\mathrm{W}_{\mathrm{DC}}$

- $N_{P V}\left(p_{\max }\right)$ is the number or count of PV customers (inverters) at $p_{\max }$

- $P_{i n v}$ is the cost premium in the high cost advanced inverter case compared to the baseline, in USD/inverter. 


\section{Results and Discussion}

This section discusses the results of our analysis on each feeder. This includes the distribution upgrade costs (upfront capital costs) as a function of penetration level for the three different spatial scenarios described in Section 2.1. For all cases, we include a range of possible costs at each penetration level based on the low, mid, and high unit cost input values. We also include information on which upgrades were selected to mitigate violations, which were all voltage related, as well as their associated costs.

Note that for all the results presented here, DPV penetration (percent) refers to the total nameplate capacity of all DPV units on the feeder (in watts) divided by the peak load of the feeder (in watts).

\subsection{J1 Feeder}

As DPV penetrations increased, the $\mathrm{J} 1$ feeder experienced voltage violations (overvoltage and voltage deviation, depending on the scenario and penetration level). We serially implemented mitigation strategies, in the order listed below, to address these issues:

1. Modify the DPV inverter set points to adjust the reactive power output of the inverters-As described in Section 2.2, we explored a set of different settings; for all cases, we selected an absorbing PF of 0.95 , which provided the greatest increase in hosting capacity.

2. Adjust the set points on the voltage regulators - We reduced the set points of the line regulators on the feeder, as well as the load tap changer (LTC) at the substation. ${ }^{8}$

3. Reconductor-We replaced sections of the feeder line experiencing voltage violations with a lower impedance conductor.

The number of required modifications and the range of unit costs for each upgrade are summarized in Table 4. The last column in this table lists the spatial DPV scenarios where the mitigation strategy was able to effectively mitigate the voltage violation and increase hosting capacity. If no hosting capacity increase was observed for a given scenario, we did not deploy that mitigation strategy or incur the associated costs. In this case, advanced inverters did not provide a hosting capacity increase for the far from the substation case, and reconductoring did not provide a hosting capacity increase for the close to the substation case. Additional detail on the analysis used to calculate hosting capacity with each of these upgrades in place has been previously published in (Ding forthcoming).

It is of note that the unit costs for adjusting the line regulator and LTC set points can be quite high, and the range of costs in the NREL Distribution Grid Integration Cost Database is large, particularly for the LTC set point change. Our interview with one utility suggests that the unit costs for regulator set point changes may include the cost of an engineer's time to determine and review potential set point changes in addition to the cost of actually changing the set points,

${ }^{8}$ LTCs are also used to regulate feeder voltage 
although further investigation is warranted to understand the drivers of these unit costs. The reasons behind the extremely large range in costs reported to change an LTC set point is unknown, although it is possible that different utilities included different costs in their numbers, and/or that the high-end costs could be associated with more extensive LTC or transformer setting upgrades. Additionally, as discussed in Section 2.4, cost for other upgrades (e.g., reconductoring) may not be representative of the full range of costs for all utilities because unit cost data are available only from a small selection of utilities in the United States.

Table 4. Summary of Upgrade Costs on the J1 Feeder

\begin{tabular}{|c|c|c|c|c|}
\hline $\begin{array}{l}\text { Upgrade } \\
\text { Selected }\end{array}$ & $\begin{array}{l}\text { Unit Cost (Low, } \\
\text { Mid, High) }\end{array}$ & $\begin{array}{l}\text { Units } \\
\text { required }\end{array}$ & $\begin{array}{l}\text { Total Cost (\$) } \\
\text { (Low, Mid, High) }\end{array}$ & $\begin{array}{l}\text { Relevant Spatial DPV } \\
\text { Deployment Scenarios }\end{array}$ \\
\hline $\begin{array}{l}\text { Advanced } \\
\text { inverters } \\
\text { functionality: } \\
\text { set all } \\
\text { inverter PF } \\
\text { to } 0.95 \\
\text { absorbing }\end{array}$ & $\begin{array}{l}\$ 0 \text { for all for the } \\
\text { baseline case, } \\
\$ 143 \text { for all for } \\
\text { the high inverter } \\
\text { cost case }\end{array}$ & $\begin{array}{l}\text { Depends on } \\
\text { penetration } \\
\text { level }\end{array}$ & & $\begin{array}{l}\text { Random and close to the } \\
\text { substation }\end{array}$ \\
\hline $\begin{array}{l}\text { Reduce line } \\
\text { voltage } \\
\text { regulator set } \\
\text { points }\end{array}$ & $\begin{array}{l}\$ 1,600, \$ 2,500 \\
\$ 3,300 / \text { regulator }\end{array}$ & 3 & $\begin{array}{l}\$ 4,800, \$ 7,500 \\
\$ 9,900\end{array}$ & All scenarios \\
\hline $\begin{array}{l}\text { Reduce } \\
\text { substation } \\
\text { LTC set } \\
\text { point }\end{array}$ & $\begin{array}{l}\$ 500, \$ 8,000 \\
\$ 26,000 / L T C\end{array}$ & 1 & $\begin{array}{l}\$ 500, \$ 8,000 \\
\$ 26,000\end{array}$ & All scenarios \\
\hline Reconductor & $\begin{array}{l}\$ 130, \$ 173 \\
\$ 258 / \mathrm{ft}\end{array}$ & $1,420.6 \mathrm{ft}$ & $\begin{array}{l}\$ 185,000 \\
\$ 245,000 \\
\$ 367,000\end{array}$ & $\begin{array}{l}\text { Random and far from the } \\
\text { substation }\end{array}$ \\
\hline
\end{tabular}

${ }^{a}$ Costs are rounded to three significant figures, reflecting the resolution or precision of this analysis.

Figure 8 maps the costs from Table 4 to distribution upgrade costs as a function of penetration for each spatial DPV deployment scenario in the baseline case. The first jump in the cost curve is associated with modifying the voltage regulator and substation LTC set points. The second, larger cost jump is due to reconductoring. Since reconductoring did not provide an additional hosting capacity increase in the close to the substation scenario, this second jump is not observed for that case. It is of note that for the far from the substation case, reconductoring was used, but provided only a small $(55 \mathrm{~kW})$ increase in the hosting capacity at a steep cost — between $\$ 185,000$ and $\$ 367,000$. It is very unlikely that any utility or PV developer incur this cost just to allow for an addition $55 \mathrm{~kW}$ to be connected to the circuit. A more likely outcome would be the prohibition of further DPV deployment in the regions far from the substation. 


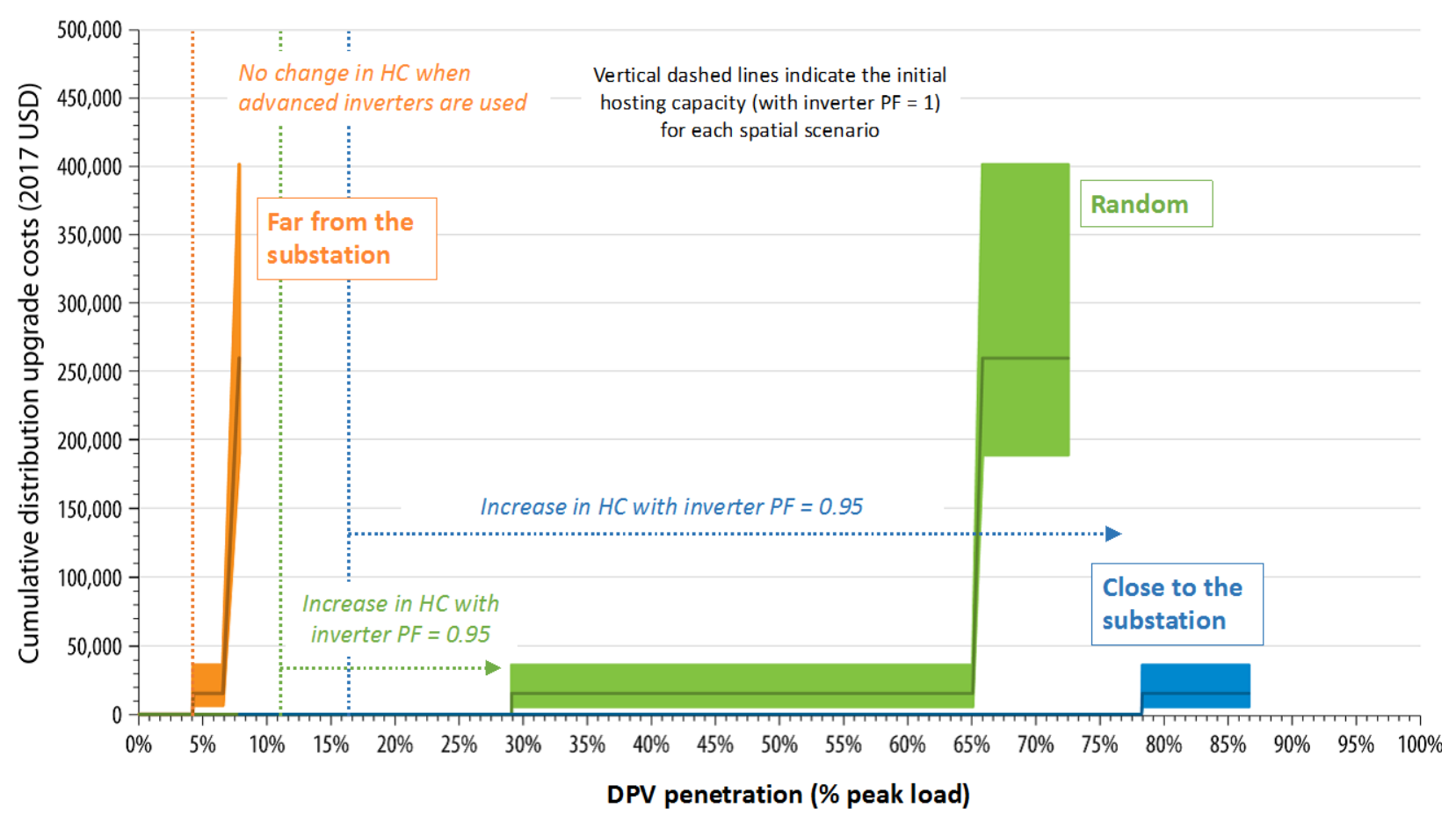

Figure 8. Cumulative distribution system upgrade cost versus penetration level on the $\mathrm{J} 1$ feeder for different spatial DPV deployment scenarios in the baseline case (no price premium for advanced inverters assumed); HC = hosting capacity

Figure 8 also shows the increases in hosting capacity (HC) possible when advanced inverter functionality was used (all PV inverters were set to have a PF of 0.95 absorbing, which provided the best result for all cases). The result depends significantly on the spatial distribution of the DPV. When the PV is clustered far from the substation, the hosting capacity was low ( $4 \%$ of peak load) and not increased by the use of advanced inverters. For the random case, the initial hosting capacity was moderate ( $11 \%$ of peak load) and increased to $30 \%$ with advanced inverters. Finally, for the case where PV is located close to the substation, the initial hosting capacity is $16 \%$, and increases substantially - to $78 \%$ - with the use of advanced inverters. Because of the potential issues with using voltage deviation as proxy for flicker discussed in Section 2.1, it is of note that if only overvoltage and thermal constraints were considered, 7.95 MW or 133\% of peak load could be integrated onto J1 in the close to the substation case without triggering upgrades beyond the advanced inverter set point changes.

We assume these increases in hosting capacity associated with the use of advanced inverters is free in the baseline scenario (Figure 8). It is possible, as discussed in Section 2.4, that in some cases there may be a premium associated with the use of an advanced inverter; for example, if the inverter is oversized to allow to supply of reactive power without reducing real power output or if the existing inverters need to be updated to enable advanced functionality. These cases correspond to our high cost advanced inverter case. The cost curves for this case are shown in Figure 9. The only difference between these results and those shown in Figure 8 is that there is a cost premium associated with each advanced inverter, resulting in a marginal increase in cost with penetration as more and more PV systems are installed for the random and close to the substation scenarios. 
For both the close to the substation and random cases, this average cost is equal to approximately

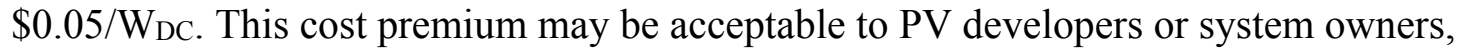
depending on project specifics, as well as the cost of alternative upgrades that would be required and who would be responsible for these costs.

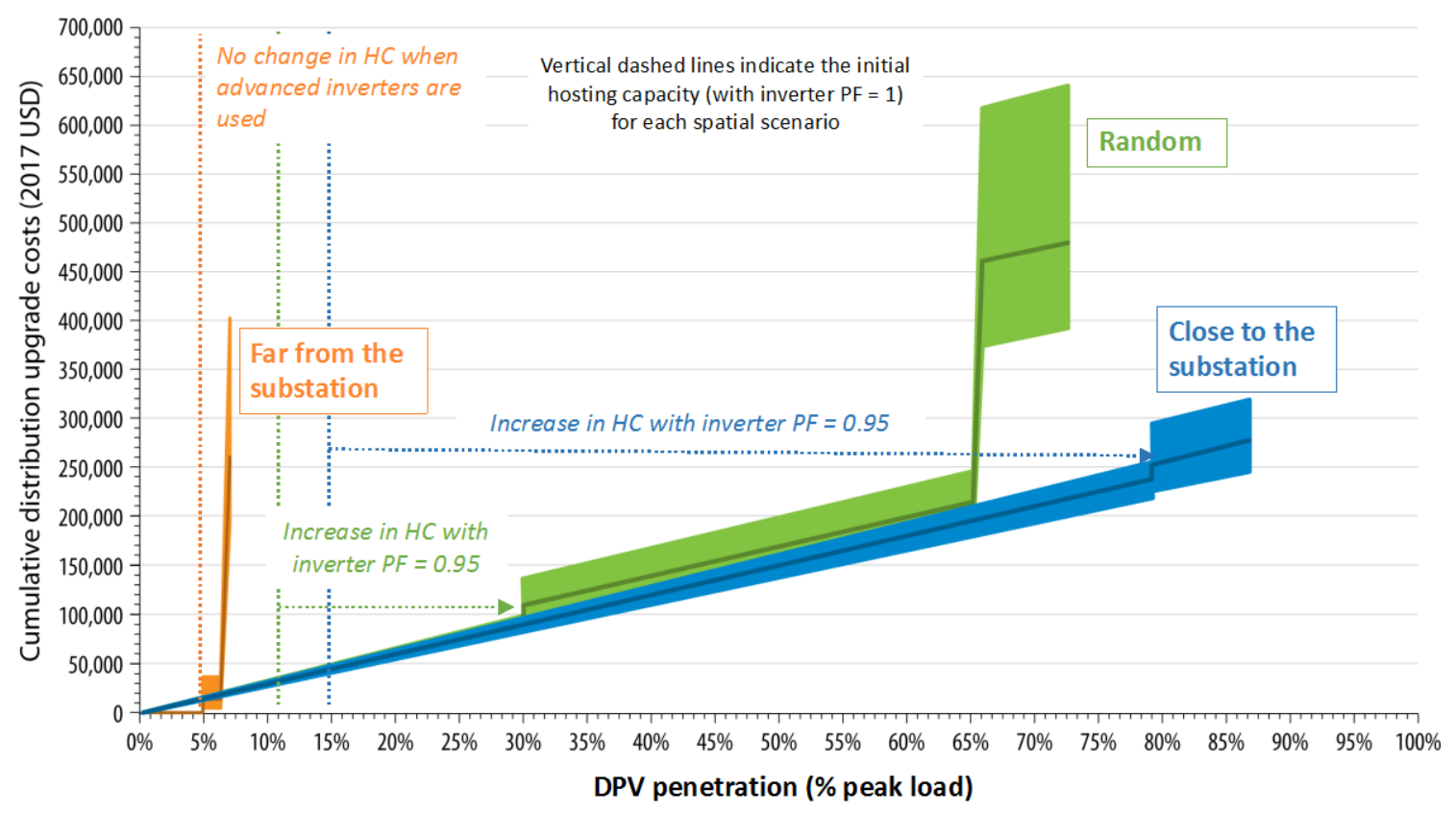

Note that on the $\mathrm{J} 1$ feeder in the far from the substation case, advanced inverters were not able to mitigate voltage issues and expand the hosting capacity (thus the curves on the top and bottom plot for this case are the same).

\section{Figure 9. Cumulative distribution system upgrade cost versus penetration level on the $\mathrm{J} 1$ feeder for different spatial DPV deployment scenarios in the high cost advanced inverter case (cost premium equal to that estimated for oversizing the rated inverter kVA by $20 \%$ ); HC = hosting capacity.}

In summary:

- J1 experienced voltage violations (overvoltage and voltage deviation) as DPV penetration levels increased beyond the hosting capacity. The hosting capacity, degree to which these violations could be mitigated using traditional utility solutions, and distribution upgrade cost per watt varied significantly depending on the spatial distribution of the PV on the feeder. The highest cost per watt of hosting capacity occurs when DPV is clustered far from the substation and the lowest cost occurs when DPV is concentrated near the substation.

- The average distribution upgrade cost per watt (defined in Section 2.5) in the baseline case were:

- With PV clustered close to the substation: $<\$ 0.01 / \mathrm{W}_{\mathrm{DC}}$

- With PV clustered far from the substation: $\$ 0.63 / \mathrm{W}_{\mathrm{DC}}$. $\$ 0.04 / \mathrm{W}_{\mathrm{DC}}$ if reconductoring is not undertaken, reducing the hosting capacity by only $55 \mathrm{~kW}$. The latter case is much more likely in practice, given that the costs of reconductoring are approximately $34 \%$ and $22 \%$ of the PV installed 
system costs for commercial and residential systems, respectively $(\mathrm{Fu}$, 2017).

- With PV randomly distributed throughout the feeder: $\$ 0.06 / \mathrm{W}_{\mathrm{DC}}$. $<\$ 0.01 / \mathrm{W}_{\mathrm{DC}}$ if reconductoring not undertaken, reducing the hosting capacity by $422 \mathrm{~kW}$.

- Using simple advanced inverter functionality provides significant increases in hosting capacity. Setting all PV inverters to have a PF of 0.95 absorbing provided the best results for all spatial scenarios on this feeder. It is likely that in many cases there will be zero or low cost for implementing these alternative PV inverter set points. However, in the case where there is a high cost associated with implementing advanced inverter functionality, the additional cost is estimated to be $\$ 0.05 / \mathrm{W}_{\text {DC }}$ on average, equal to approximately $2.7 \%$ and $1.8 \%$ of the PV installed system costs for commercial and residential systems, respectively $(\mathrm{Fu}, 2017)$.

- Reconductoring is an expensive option for mitigating voltage impacts of DPV. While this may be required to increase the hosting capacity in some cases, reconductoring costs could be avoided by using a combination of advanced inverters and installing DPV in low impact locations.

- A summary of results for J1 compared to the other two feeders are included in Section 3.4 .

\subsection{Feeder A}

As with the $\mathrm{J} 1$ feeder, voltage violations (overvoltage and voltage deviation, depending on the scenario and penetration level) limited the amount of DPV that could be integrated onto the Feeder A. However, because of the differences in existing equipment on the feeder, as well as differences in feeder characteristics, different mitigation strategies were used:

1. Modify the DPV inverter set points to adjust the reactive power output of the inverters. As for J1, we implemented this mitigation strategy first. We simulated several different set point options, and selected the one that resulted in the greatest increase in hosting capacity for each spatial scenario. For this feeder, a fixed PF of 0.95 absorbing provided the best result for the random and far from the substation cases, while volt/VAR control worked best for the close to the substation case.

2. Add voltage regulators. Unlike on the $\mathrm{J} 1$ feeder, there were no existing line voltage regulators and no substation LTC present on the Feeder A. Therefore, we next added a new line regulator and an LTC at the substation transformer to mitigate voltage violations. We saw that both of these upgrades needed to be undertaken simultaneously to increase the hosting capacity. The set points for each of these devices were selected to provide the best result. Adding additional regulators did not expand the hosting capacity further for any of the scenarios.

For this circuit, reconductoring was not found to be an effective strategy for mitigating overvoltage issues and achieving meaningful increases in hosting capacity, and thus was not used. Additional detail on the iterative hosting capacity analysis for this feeder is included in (Ding forthcoming). 
Mitigation strategies and their unit costs are summarized in Table 5. The low, mid, and high cost for new line regulators corresponds to the minimum, average, and maximum of the total installed cost for $12 \mathrm{kV}$ and $12.7 \mathrm{kV}$ line regulators from the data in the NREL Distribution Grid Integration Unit Cost Database. We could only find one data point on the cost of adding an LTC to a substation transformer from a 1997 report from Pacific Northwest National Laboratory (Dagle and Brown 1997). The cost cited in that report was \$203k per transformer; converting this value into 2017 dollars to account for inflation, we obtained $\$ 310,439$, which was rounded to the $\$ 310,000$ listed in Table 5 to avoid false precision.

Table 5. Summary of Upgrade Costs on the Feeder $A^{a}$

\begin{tabular}{|c|c|c|c|c|}
\hline $\begin{array}{l}\text { Upgrade } \\
\text { Selected }\end{array}$ & $\begin{array}{l}\text { Unit Cost (Low, } \\
\text { Mid, High) }\end{array}$ & $\begin{array}{l}\text { Units } \\
\text { Required }\end{array}$ & $\begin{array}{l}\text { Total Cost (Low, } \\
\text { Mid, High) }\end{array}$ & $\begin{array}{l}\text { Relevant Spatial } \\
\text { DPV Deployment } \\
\text { Scenarios }\end{array}$ \\
\hline $\begin{array}{l}\text { Advanced } \\
\text { inverter } \\
\text { functionality: set } \\
\text { all inverter PF to } \\
0.95 \text { absorbing } \\
\text { or use volt/VAR } \\
\text { control }\end{array}$ & $\begin{array}{l}\$ 0 \text { for all for the } \\
\text { baseline case, } \$ 143 \\
\text { for all for the high } \\
\text { inverter cost case }\end{array}$ & $\begin{array}{l}\text { Depends on } \\
\text { penetration } \\
\text { level }\end{array}$ & & All scenarios \\
\hline $\begin{array}{l}\text { New line voltage } \\
\text { regulator }^{b}\end{array}$ & $\begin{array}{l}\$ 150,000, \\
\$ 166,000, \$ 183,000\end{array}$ & 1 & $\begin{array}{l}\$ 150,000, \$ 166,000 \\
\$ 183,000\end{array}$ & All scenarios \\
\hline $\begin{array}{l}\text { New LTC at the } \\
\text { substation } \\
\text { transformer }^{b}\end{array}$ & $\begin{array}{l}\$ 310,00, \$ 310,000 \\
\$ 310,000\end{array}$ & 1 & $\begin{array}{l}\$ 310,00, \$ 310,000 \\
\$ 310,000\end{array}$ & All scenarios \\
\hline
\end{tabular}

${ }^{a}$ Costs are rounded to three significant figures, reflecting the resolution or precision of this analysis.

b These upgrades were undertaken simultaneously

Costs shown in Table 5 were used to create curves of cumulative distribution upgrade cost versus DPV penetration, shown in Figure 10 for the baseline case. We can see that the results are quite different for the Feeder A and the $\mathrm{J} 1$ feeder. Unlike on J1, the initial hosting capacities are similar for the three spatial scenarios on the Feeder A (between 14\% and 15\% of peak load for all scenarios). The jump in the cost curves shown in Figure 10 corresponds to the addition of the voltage regulator and the LTC at the substation transformer. The increase in the hosting capacity enabled by installing these devices was also similar in all three scenarios $(862 \mathrm{~kW}, 605 \mathrm{~kW}$, and $637 \mathrm{~kW}$ for the random, close to the substation, and far from the substation scenarios, respectively).

As illustrated in Figure 10, advanced inverters increased the hosting capacity in all three scenarios. Interesting, advanced inverters provided the greatest increase in hosting capacity in the far from the substation case, providing a $21 \%$ absolute increase in hosting capacity, compared to $5 \%$ and $12 \%$ for the random and close to the substation scenarios. While many feeders do have higher hosting capacity with PV closer to the substation, this is not the case for all feeders, as illustrated by our results for Feeder A, which representative of a larger set of systems in California as discussed in Section 2.3. There are several reasons for the more similar initial hosting capacities for each spatial scenario and this larger increase in hosting capacity for the far 
from the substation case: 1) Feeder A is shorter (about half as long as J1), and thus the spatial DPV distributions are more similar for all three spatial scenarios, 2) Feeder A is more heavily loaded, and 3) the PV buses close to the substation are more likely to have violations for Feeder A because of the specific characteristics of those buses. For the interested reader, (Ding 2017) contains additional data illustrating the variation in hosting capacity for a broader set of feeders.

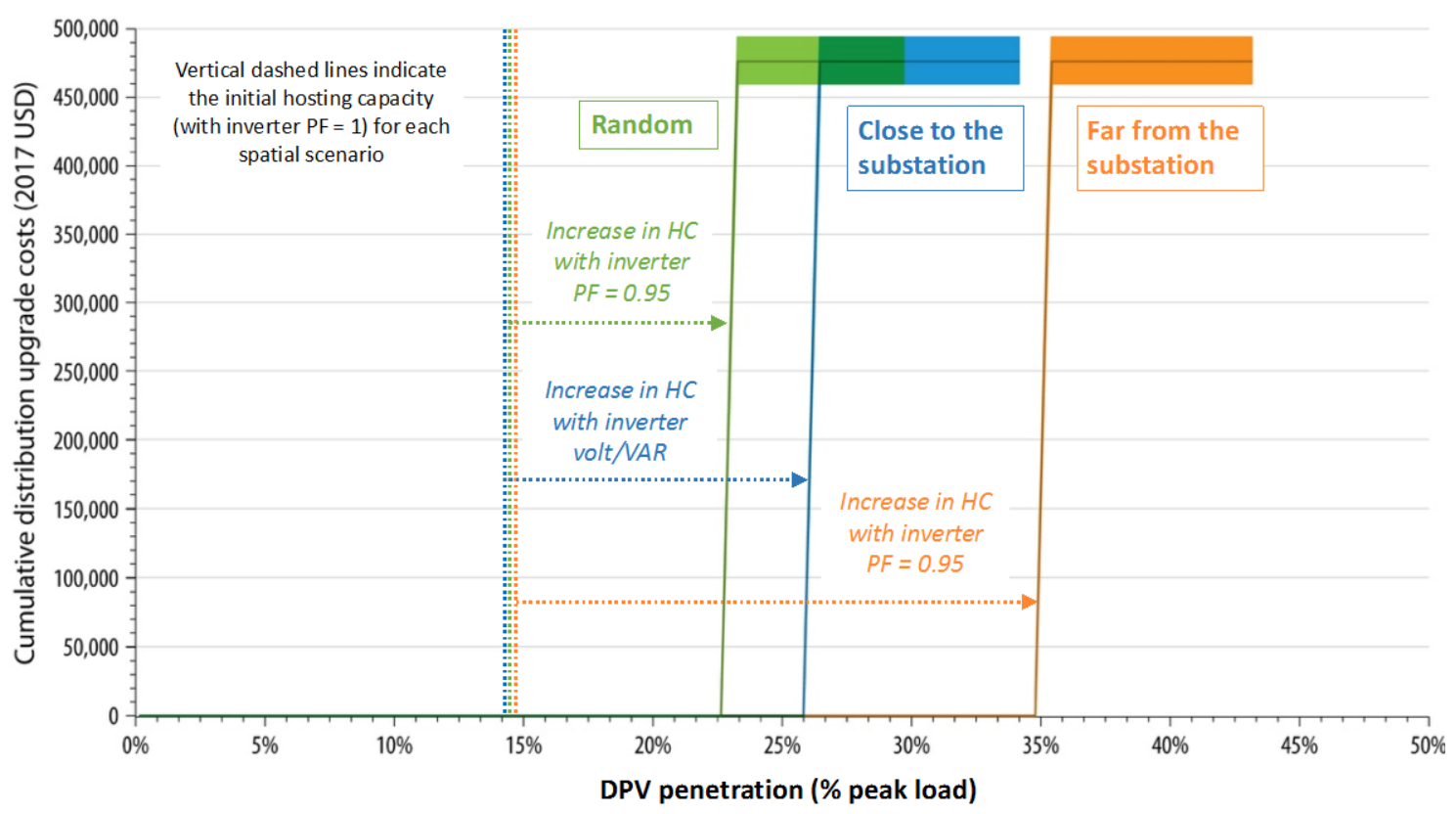

Figure 10. Cumulative distribution system upgrade cost versus penetration level on the Feeder $A$ for the three spatial DPV deployment scenarios in the baseline case (no price premium for advanced inverters). $\mathrm{HC}=$ hosting capacity.

The marginal cost of adding a new voltage regulator and a new LTC at the substation for the mid cost case is $\$ 0.87 / \mathrm{W}_{D C}, \$ 0.73 / \mathrm{W}_{\mathrm{DC}}$, and $\$ 0.73 / \mathrm{W}_{\mathrm{DC}}$ for the random, close to the substation, and far from the substation scenarios, respectively. These costs are equal to roughly $26-31 \%$ of the total installed cost of residential PV systems in the United States in 2017, or $40-47 \%$ of the total installed cost of a $200 \mathrm{~kW}$ commercial PV system (Fu 2017). The average cost (across all penetration levels) of distribution upgrades in the mid-cost case was $\$ 0.21 / \mathrm{W}_{\mathrm{DC}}, \$ 0.18 / \mathrm{W}_{\mathrm{DC}}$, and $\$ 0.14 / \mathrm{WDC}$, for the random, close to the substation, and far from the substation cases, respectively. Whether or not these costs are acceptable will depend on how they are allocated among the utility and PV generators, as well as the goals of the utilities, regulators, and customers in a given region.

Figure 11 shows the upgrade costs in the high cost advanced inverter case. Again, this case is meant to illustrate the sensitivity of distribution costs to the cost premium associated with advanced inverters that may be observed in some special cases. As can be seen from the plot, the costs associated with installing a new voltage regulator and LTC at the substation transformer are much more significant than the cumulative costs associated with advanced inverter deployment, even in the high cost case. 


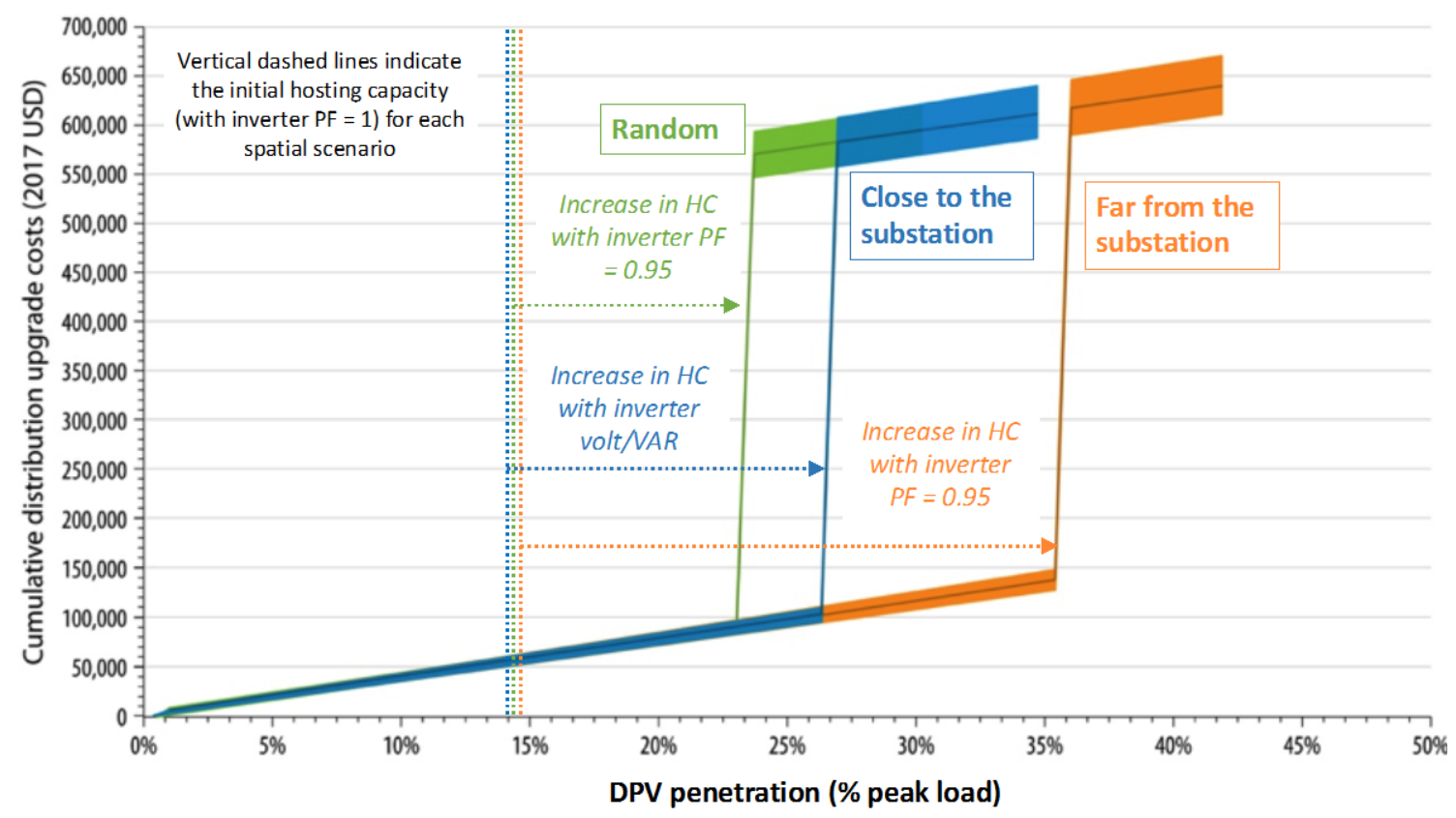

Figure 11. Cumulative distribution system upgrade cost versus penetration level on the Feeder $A$ for the three spatial DPV deployment scenarios in the high advanced inverter case (cost premium equal to that estimated for oversizing the rated inverter kVA by $20 \%$ ). HC = hosting capacity.

In summary:

- The Feeder A experienced voltage violations (overvoltage and voltage deviation) as DPV penetration levels increased beyond the hosting capacity. The initial hosting capacity was very similar for all three spatial scenarios, possibly because the Feeder A is much shorter than J1 and was more heavily loaded. Additionally, the PV buses close to the substation are more likely to have violations for Feeder A because of the specific characteristics of those buses.

- Using advanced inverter functionality provided a $5 \%$ to $21 \%$ absolute increase in hosting capacity compared to the case where all inverters have unity PF. Setting all PV inverters to have a PF of 0.95 absorbing provided the best result for the random and far from the substation scenarios, while volt/VAR control was most effective for increasing the hosting capacity when PV was concentrated close to the substation. It is likely that in many cases there will be zero or low cost for implementing these alternative PV inverter set points, meaning that penetrations between $20 \%$ and $36 \%$ could be achieved at little to no cost. In the case where there is a high cost premium associated with the use of advanced inverters, these still present a much lower cost option to mitigating voltage violations than installing traditional voltage regulation equipment.

- After advanced inverters were deployed, installing both a new voltage regulator and a new LTC at the substation transformer simultaneously was required to further increase the hosting capacity. The total cost for these upgrades was high, with the installation of the substation LTC being particularly costly. However, there is limited data available on the unit costs associated with installing a new LTC, and these costs likely vary significantly from site-to-site. 
- A summary of results for Feeder A compared to the other two feeders are included in Section 3.4.

\subsection{Feeder B}

Like the $\mathrm{J} 1$ and Feeder A, the initial hosting capacity on Feeder B was limited by voltage violations. However, a thermal issue - specifically, an overload on multiple secondary transformers - arose at higher penetration levels for the close to the substation case. The mitigation strategies used to address these voltage and thermal violations, deployed in this order, were:

1. Modify the DPV inverter set points to adjust the reactive power output of the inverters-As for the other two feeders, we implemented this mitigation strategy first. We simulated several different set point options, and selected the one that resulted in the greatest increase in hosting capacity for each spatial scenario. For this feeder, a fixed PF of 0.95 absorbing provided the best result for all scenarios.

2. Add a new capacitor and reduce the substation LTC set point-For the close to the substation case, adding a distribution capacitor to flatten the voltage profile along the feeder, and then reducing the set point on the existing LTC successfully mitigated overvoltage issuess. The capacitor size was selected to be the minimum standard size which that mitigated the violation. For the random and close to the substation cases, this strategy was not effective (no increase in hosting capacity was observed for the close to the substation scenario, and only a very minor increase of $3 \mathrm{~kW}$ in the random scenario). In fact, for these two scenarios, we could not identify any traditional mitigation strategy that could address the voltage violations and increase the hosting capacity beyond what was achievable using advanced inverters.

3. Increase the size of overloaded secondary transformers - We identified ten secondary transformers that were overloaded. We increased the size to mitigate the issue, but eventually these secondary transformers became overloaded again. Further increasing the size of these transformers would require the use of large transformers not standard for secondary networks, and would incur a significant expense. Thus, we did not upgrade the secondary transformers a second time to address these new thermal overloads, but instead ended the simulation.

The unit costs and number of units required for each of these upgrades is shown in Table 6 . These inputs were used to calculate the cumulative upgrade costs versus penetration level. In Figure 12, we show these costs for the close to the substation scenario in the baseline case. The other two scenarios are not shown because only advanced inverters were able to mitigate violations for those cases, and the use of advanced inverters incurs zero marginal cost in the baseline case. The increases in hosting capacity enabled by the use of advanced inverters for those scenarios, however, are shown in Figure 13 and discussed below. 
Table 6. Summary of Upgrade Costs on Feeder Ba

\begin{tabular}{|c|c|c|c|c|}
\hline $\begin{array}{l}\text { Upgrade } \\
\text { Selected }\end{array}$ & $\begin{array}{l}\text { Unit Cost (Low, } \\
\text { Mid, High) }\end{array}$ & $\begin{array}{l}\text { Units } \\
\text { Required }\end{array}$ & $\begin{array}{l}\text { Total Cost (Low, } \\
\text { Mid, High) }\end{array}$ & $\begin{array}{l}\text { Relevant Spatial } \\
\text { DPV Deployment } \\
\text { Scenarios }\end{array}$ \\
\hline $\begin{array}{l}\text { Advanced } \\
\text { inverters } \\
\text { functionality: set } \\
\text { all inverter PF to } \\
0.95 \text { absorbing }\end{array}$ & $\begin{array}{l}\$ 0 \text { for all for the } \\
\text { baseline case, } \$ 143 \\
\text { for all for the high } \\
\text { inverter cost case }\end{array}$ & $\begin{array}{l}\text { Depends on } \\
\text { penetration } \\
\text { level }\end{array}$ & & All scenarios \\
\hline $\begin{array}{l}\text { New 3-phase, } \\
\text { 300kVar } \\
\text { capacitor }\end{array}$ & $\begin{array}{l}\$ 6,000, \$ 8,290 \\
\$ 10,700\end{array}$ & 1 & $\begin{array}{l}\$ 6,000, \$ 8,290 \\
\$ 10,700\end{array}$ & $\begin{array}{l}\text { Close to the } \\
\text { substation only }\end{array}$ \\
\hline $\begin{array}{l}\text { Reduce LTC set } \\
\text { point }\end{array}$ & $\begin{array}{l}\$ 500, \$ 8,000 \\
\$ 26,000\end{array}$ & 1 & $\begin{array}{l}\$ 500, \$ 8,000 \\
\$ 26,000\end{array}$ & $\begin{array}{l}\text { Close to the } \\
\text { substation only }\end{array}$ \\
\hline $\begin{array}{l}\text { New 3-phase, } \\
50 \mathrm{kVA} \\
\text { transformer } \\
(\mathrm{OH})^{\mathrm{b}}\end{array}$ & $\begin{array}{l}\$ 10,400, \$ 10,400 \\
\$ 10,400\end{array}$ & 1 & $\begin{array}{l}\$ 10,400, \$ 10,400 \\
\$ 10,400\end{array}$ & $\begin{array}{l}\text { Close to the } \\
\text { substation only }\end{array}$ \\
\hline $\begin{array}{l}\text { New 3-phase, } \\
\text { 100kVA } \\
\text { transformer } \\
(\mathrm{OH})^{\mathrm{b}}\end{array}$ & $\begin{array}{l}\$ 15,600, \$ 32,500 \\
\$ 49,300\end{array}$ & 9 & $\begin{array}{l}\$ 140,000, \$ 292,000 \\
\$ 444,000\end{array}$ & $\begin{array}{l}\text { Close to the } \\
\text { substation only }\end{array}$ \\
\hline
\end{tabular}

${ }^{a}$ Costs are rounded to three significant figures, reflecting the resolution or precision of this analysis.

b $\mathrm{OH}=$ overhead

As shown in Figure 12, the use of advanced inverters (inverters with a $0.95 \mathrm{PF}$ absorbing) enables approximately at $16 \%$ increase (absolute) in the hosting capacity. The subsequent small jump in cumulative distribution upgrade costs around $50 \%$ penetration is associated with the installation of the new capacitor and reduction of the substation LTC set point. With the use of advanced inverters and these relatively low cost upgrades, penetration levels of $61 \%$ could be achieved at an average cost between $\$ 0.005 / \mathrm{WDC}_{\text {DC }} \$ 0.03 / \mathrm{WDC}$.

The larger jump in costs seen at $61 \%$ penetration in Figure 12 is caused by the installation of the ten new (larger) secondary transformers, which enable an addition $15 \%$ absolute increase in the hosting capacity, but at a steep cost. In the high-cost case, the marginal cost associated with upgrading all the transformers is $\$ 1.51 / \mathrm{W}_{\mathrm{DC}}$, corresponding to $54 \%$ and $82 \%$ of the 2017 total installed cost for residential and commercial PV systems, respectively (Fu 2017). Even in the low-cost case, the marginal cost associated with these upgrades is $\$ 0.50 / \mathrm{WDC}_{\text {DC }}$ This results in an average cost (for the mid-cost case) of $\$ 0.21 / \mathrm{WDC}_{\mathrm{DC}}$ for integrating PV with a capacity of $76 \%$ of peak load, compared to $\$ 0.01 / \mathrm{W}_{\mathrm{DC}}$ average (for the mid-cost case) required to integrate $\mathrm{PV}$ with a capacity of $61 \%$ of peak load.

The broad uncertainty bands around the total cost for these transformers is driven by the wide range in 100kVA transformer costs reported in the NREL Distribution Grid Integration Unit Cost Database. This variation in unit cost is amplified when total upgrade costs for this feeder are calculated, since nine new 100kVA transformers are required. 


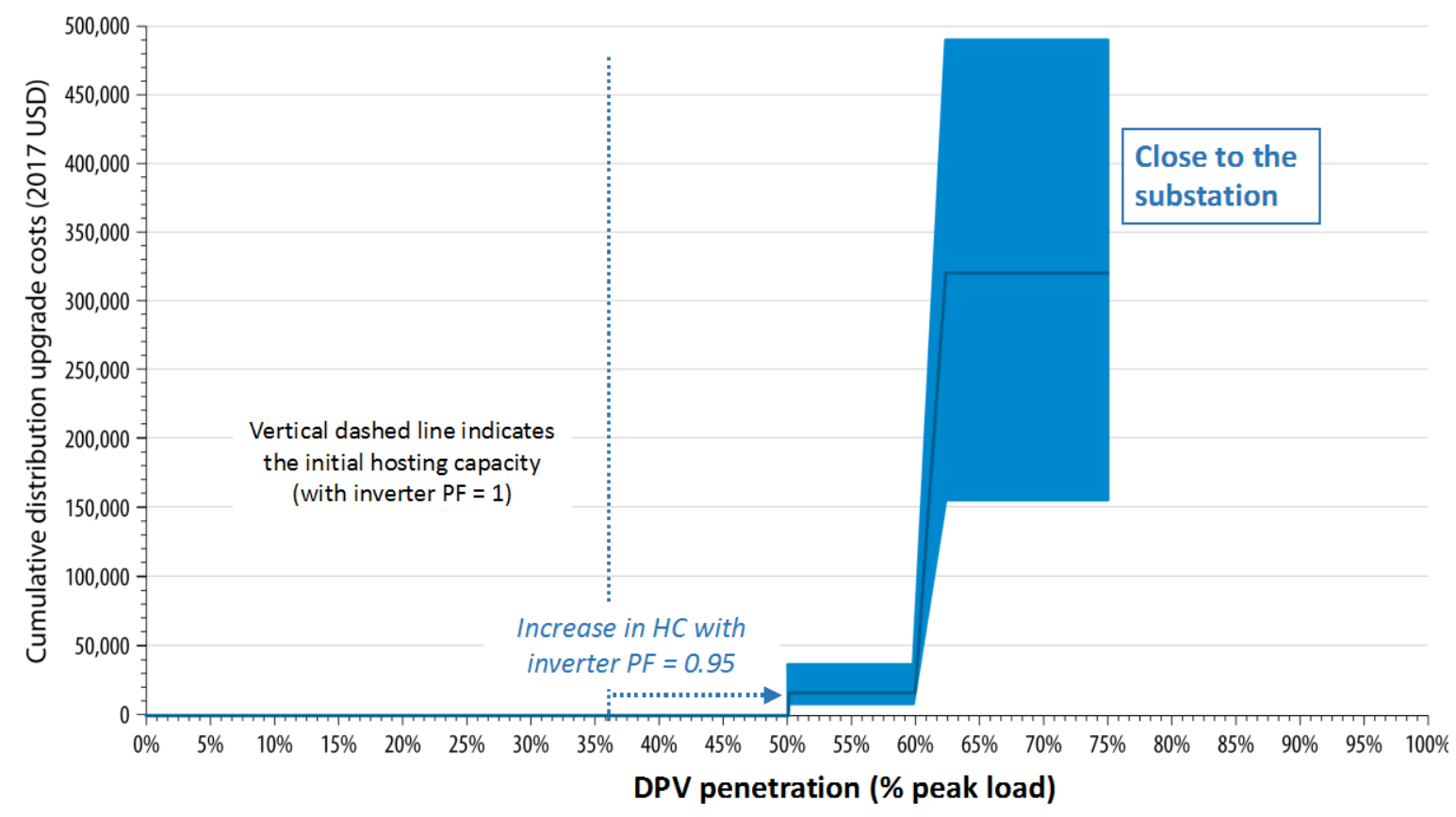

Figure 12. Cumulative distribution system upgrade cost versus penetration level on Feeder $B$ for the baseline case (no price premium for advanced inverters). Only the close to the substation costs are shown because we found that only advanced inverters (which incur zero cost in the baseline case) were able to effectively increase the hosting capacity on this circuit for the random and far from the substation scenarios. $\mathrm{HC}=$ hosting capacity.

Figure 13 shows the cumulative upgrade costs versus penetration level for the high-cost advanced inverter case. All three spatial scenarios are shown in this plot. As shown in the figure, advanced inverters resulted in only a small ( $14 \mathrm{~kW}$ or $0.7 \%$ peak load) increase in the hosting capacity for the far from the substation case. For the random scenario, advanced inverters enabled a slightly greater ( $164 \mathrm{~kW}$ or $8.2 \%$ peak load) increase in the hosting capacity. For the close to the substation scenario, the costs associated with upgrading the secondary transformers still dwarf the costs of the advanced inverters. 


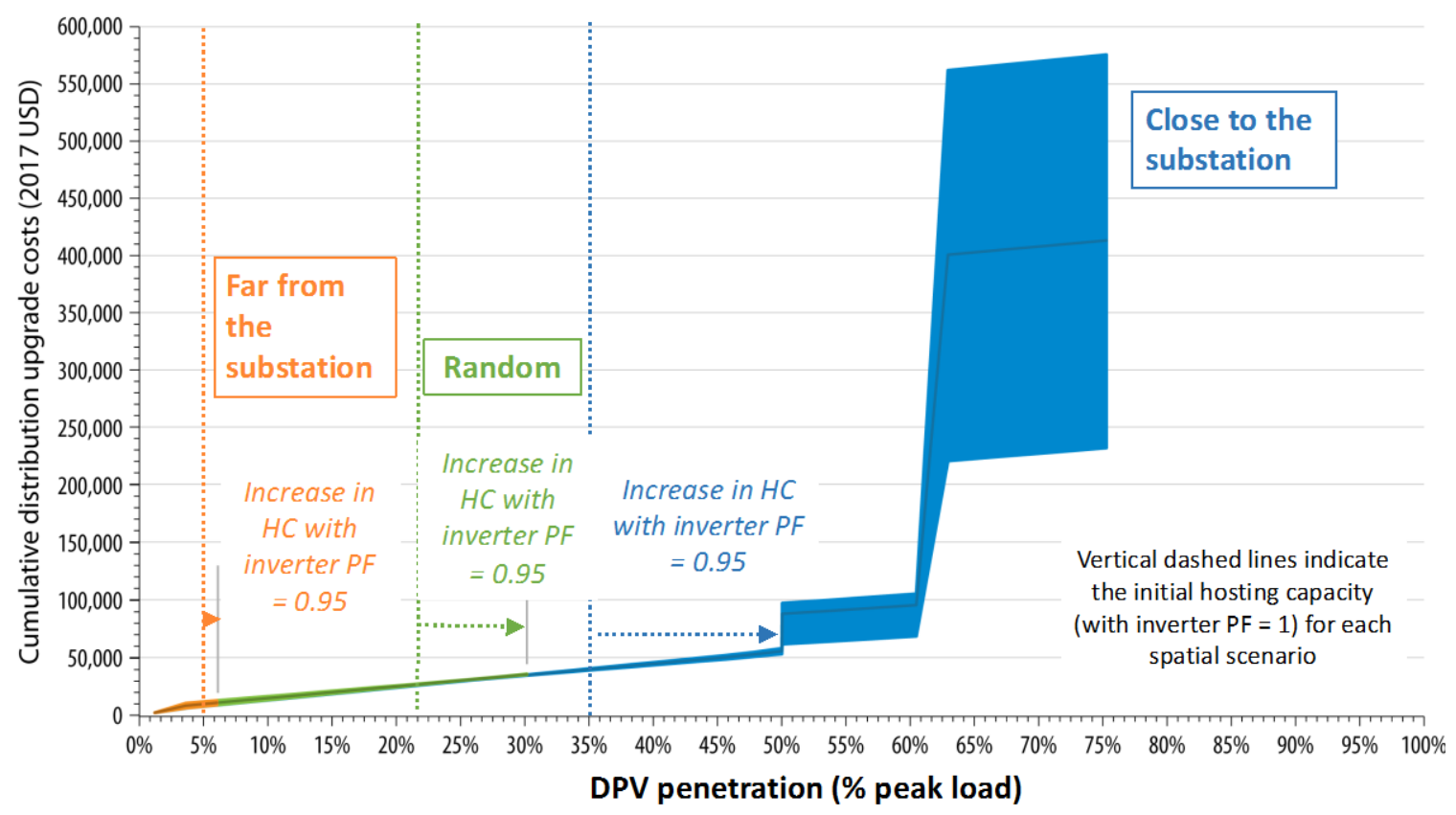

Figure 13. Cumulative distribution system upgrade cost versus penetration level on Feeder $B$ for the three spatial DPV scenarios for the high advanced inverter case (cost premium equal to that estimated for oversizing the rated inverter kVA by $20 \%$ ). HC = hosting capacity.

In summary:

- Feeder B experienced voltage violations as DPV penetration levels increased beyond the hosting capacity. For the far to the substation and random scenarios, only advanced inverters could effectively mitigate these violations, although for the far from the subtation case, the increase in hosting capacity with advanced inverters was very small.

- The initial hosting capacity and degree to which advanced inverters to increased the hosting capacity was highly dependent on the spatial distribution of the DPV on the feeder. The highest average cost per watt and lowest hosting capacity occured when DPV is clustered far from the substation, and the lowest cost occured when DPV is concentrated near the substation.

- For the close to the substation scenario, $61 \%$ penetration could be reached using advanced inverters and voltage regulation equipment (adding capacitor banks and reducing the LTC set point) at low cost $\left(\$ 0.01 / \mathrm{W}_{\mathrm{DC}}\right.$ average cost $)$. To get to even higher penetrations $(77 \%)$, expensive secondary transformer upgrades were required to mitigate thermal overloads at a marginal upgrade cost of $\$ 1.06 / \mathrm{W}_{\mathrm{DC}}$, equal to approximately $57 \%$ and $38 \%$ of PV installed system costs for commercial and residential systems, respectively $(\mathrm{Fu}, 2017)$. These secondary transformer upgrades also result in a significantly higher average cost of $\$ 0.21 / \mathrm{W}_{\text {DC }}$ across all penetration levels (see Section 2.5 for the definition of marginal and average costs).

- A summary of results for Feeder B compared to the other two feeders are included in Section 3.4. 


\subsection{Discussion}

Table 7 summarizes the cumulative distribution upgrade costs (for the mid unit cost case) and achievable penetration levels for all three feeders and spatial DPV distribution scenarios for the baseline case. The technical limits are defined as those for which we could mitigate voltage and/or thermal violations using the set of solutions (traditional utility solutions and advanced inverters) described in Section 2.2. In contrast, the economic values listed in the table correspond to the limits in how much DPV could be added without requiring an investment greater that is unlikely to be made in practice given the amount of hosting capacity gain. Specifically, if the marginal cost of an upgrade (as defined in Section 2.5) exceeds 30\% of the average cost of a commercial PV installed system in the United States $\left(\$ 1.85 / \mathrm{W}_{\mathrm{DC}}\right)$, we consider that upgrade uneconomical.

As can be seen from the table, average costs vary significantly between feeders and spatial distribution scenarios, ranging from $\$ 0$ to $\$ 0.04 / \mathrm{W}_{\mathrm{DC}}$ for the baseline scenario and up to $\$ 0.07 / \mathrm{W}_{\mathrm{DC}}$ for the high inverter cost case when only the economical solutions are considered. If uneconomical investments are made, costs could be as high as $\$ 0.63 / \mathrm{W}_{\mathrm{DC}}$. Costs can be minimized by guiding DPV into low-cost integration regions and by using advanced inverters; in fact, in many cases, high penetrations could be reached simply by changing the fixed PF of the inverters to 0.95 , a solution that likely has zero marginal cost.

In the high-cost advanced inverter case, the costs shown in Table 7 are increased by approximately $\$ 0.05 / \mathrm{W}_{D C}$ in almost all cases, with the highest increase being $\$ 0.07 / \mathrm{WDC}_{\mathrm{DC}}$. 
Table 7. Summary of Cumulative Costs (Mid Unit Cost Case) and Achievable Penetration Levels on Studied Three Feeders for the Baseline Case

\begin{tabular}{|c|c|c|c|}
\hline & Close to the Substation & Random & Far from the Substation \\
\hline \multirow[t]{5}{*}{$\begin{array}{l}\text { J1 } \\
\text { Feeder }\end{array}$} & \multirow[t]{2}{*}{$\begin{array}{l}\text { Max. economical } \\
\text { (technical) DPV } \\
\text { penetration }=5,210 \mathrm{~kW} \\
(5,210 \mathrm{~kW})\end{array}$} & $\begin{array}{l}\text { Max. economical (technical) } \\
\text { DPV penetration }=3,940 \mathrm{~kW} \\
(4,362 \mathrm{~kW})\end{array}$ & $\begin{array}{l}\text { Max. economical (technical) } \\
\text { DPV penetration }=361 \mathrm{~kW} \\
(416 \mathrm{~kW})\end{array}$ \\
\hline & & \multirow{2}{*}{$\begin{array}{l}\text { Cumulative cost at max. } \\
\text { economical (technical) DPV } \\
\text { penetration }=\$ 15,500 \\
(\$ 261,000)\end{array}$} & \multirow{2}{*}{$\begin{array}{l}\text { Cumulative cost at max. } \\
\text { economical (technical) DPV } \\
\text { penetration }=\$ 15,500 \\
(\$ 261,000)\end{array}$} \\
\hline & \multirow{3}{*}{$\begin{array}{l}\text { Cumulative cost at max. } \\
\text { economical (technical) } \\
\text { DPV penetration = } \\
\$ 15,500(\$ 15,500) \\
\text { Economical (technical) } \\
\text { average cost per watt }= \\
<\$ 0.01 / \mathrm{W}_{\mathrm{DC}}\left(<\$ 0.01 / \mathrm{W}_{\mathrm{DC}}\right)\end{array}$} & & \\
\hline & & Economical (technical) & Economical (technical) \\
\hline & & $\begin{array}{l}\text { average cost per watt }= \\
<\$ 0.01 / \mathrm{W}_{\mathrm{DC}}\left(\$ 0.06 / \mathrm{W}_{\mathrm{DC}}\right)\end{array}$ & $\begin{array}{l}\text { average cost per watt }= \\
\$ 0.04 / \mathrm{W}_{\mathrm{DC}}\left(\$ 0.63 / \mathrm{W}_{\mathrm{DC}}\right)\end{array}$ \\
\hline \multirow[t]{5}{*}{$\begin{array}{l}\text { Feeder } \\
\text { A }\end{array}$} & \multirow{2}{*}{$\begin{array}{l}\text { Max. economical } \\
\text { (technical) DPV } \\
\text { penetration }=2,045 \mathrm{~kW} \\
(2,650 \mathrm{~kW})\end{array}$} & $\begin{array}{l}\text { Max. economical (technical) } \\
\text { DPV penetration }=1,485 \mathrm{~kW} \\
(2,347 \mathrm{~kW})\end{array}$ & $\begin{array}{l}\text { Max. economical (technical) } \\
\text { DPV penetration }=2,743 \mathrm{~kW} \\
(3,380 \mathrm{~kW})\end{array}$ \\
\hline & & \multirow{2}{*}{$\begin{array}{l}\text { Cumulative cost at max. } \\
\text { economical (technical) DPV } \\
\text { penetration }=\$ 0(\$ 476,000)\end{array}$} & \multirow{2}{*}{$\begin{array}{l}\text { Cumulative cost at max. } \\
\text { economical (technical) DPV } \\
\text { penetration = } \$ 0(\$ 476,000\end{array}$} \\
\hline & \multirow{3}{*}{$\begin{array}{l}\text { Cumulative cost at max. } \\
\text { economical (technical) } \\
\text { DPV penetration }=\$ 0 \\
(\$ 476,000) \\
\text { Economical (technical) } \\
\text { average cost per watt = } \\
\$ 0 / W_{D C}\left(\$ 0.18 / W_{D C}\right)\end{array}$} & & \\
\hline & & \multirow{2}{*}{$\begin{array}{l}\text { Economical (technical) } \\
\text { average cost per watt = } \\
\$ 0 / \mathrm{W}_{D C}\left(\$ 0.20 / \mathrm{W}_{D C}\right)\end{array}$} & \multirow{2}{*}{$\begin{array}{l}\text { Economical (technical) } \\
\text { average cost per watt = } \\
\$ 0 / W_{D C}\left(\$ 0.14 / W_{D C}\right)\end{array}$} \\
\hline & & & \\
\hline \multirow[t]{5}{*}{$\begin{array}{l}\text { Feeder } \\
\text { B }\end{array}$} & \multirow{2}{*}{$\begin{array}{l}\text { Max. economical } \\
\text { (technical) DPV } \\
\text { penetration }=1,222 \mathrm{~kW} \\
(1,515 \mathrm{~kW})\end{array}$} & $\begin{array}{l}\text { Max. economical (technical) } \\
\text { DPV penetration }=609 \mathrm{~kW} \\
(612 \mathrm{~kW})\end{array}$ & $\begin{array}{l}\text { Max. economical (technical) } \\
\text { DPV penetration }=123 \mathrm{~kW} \\
(123 \mathrm{~kW})\end{array}$ \\
\hline & & \multirow{2}{*}{$\begin{array}{l}\text { Cumulative cost at max. } \\
\text { economical (technical) DPV } \\
\text { penetration = } \$ 0(\$ 16,000)\end{array}$} & \multirow{2}{*}{$\begin{array}{l}\text { Cumulative cost at max. } \\
\text { economical (technical) DPV } \\
\text { penetration }=\$ 0(\$ 0)\end{array}$} \\
\hline & $\begin{array}{l}\text { Cumulative cost at max. } \\
\text { economical (technical) }\end{array}$ & & \\
\hline & $\begin{array}{l}\text { DPV penetration }= \\
\$ 16,000(\$ 319,000)\end{array}$ & \multirow{2}{*}{$\begin{array}{l}\text { Economical (technical) } \\
\text { average cost per watt = } \\
\$ 0 / \mathrm{W}_{D C}\left(\$ 0.03 / \mathrm{W}_{D C}\right)\end{array}$} & \multirow{2}{*}{$\begin{array}{l}\text { Economical (technical) } \\
\text { average cost per watt }= \\
\$ 0 / W_{D C}\left(\$ 0 / W_{D C}\right)\end{array}$} \\
\hline & $\begin{array}{l}\text { Economical (technical) } \\
\text { average cost per watt }= \\
\$ 0.01 / \mathrm{W}_{\mathrm{DC}}\left(\$ 0.21 / \mathrm{W}_{\mathrm{DC}}\right)\end{array}$ & & \\
\hline
\end{tabular}




\section{Conclusions and Future Work}

This work investigated the potential distribution upgrade costs associated with integrating high penetrations of DPV on three real feeders in the United States, assuming current standard analysis practices and mitigation solutions are used. We found that capital costs ranged from $\$ 0$ to $\$ 0.04 / \mathrm{W}_{\mathrm{DC}}$ for the baseline scenario and up to $\$ 0.07 / \mathrm{W}_{\mathrm{DC}}$ for the high inverter cost case when only the economical solutions are considered. Both costs and achievable penetration levels were highly dependent on the circuit and spatial distribution of DPV on the circuit; however, in almost all cases, basic advanced inverters functions could allow for significant expansion of the hosting capacity at a low or zero marginal cost. Further analysis on whether oversizing advanced inverters - and incurring an associated cost - is necessary is also warranted. For example, it would be useful to analyze how much real power output is reduced if the inverter is not oversized and the PF is set to 0.95 in a set of different locations. Additionally, it would be useful to incorporate realistic PV adoption models into this analysis order to inform most likely outcomes in different regions; however, models that can predict adoption at the household level (necessary to evaluate impacts at the feeder level) are not yet fully developed.

Finally, future analysis using quasi-static time series analysis that can capture the time-varying behavior of PV, loads, and voltage regulating devices is needed. This would provide a more realistic picture of hosting capacity and costs, and allow for consideration of a broader set of mitigation strategies, including battery energy storage and advanced controls schemes. Additionally, it would allow for accounting of potential impacts of DPV on operations and maintenance costs, by providing information on changes in the number of device operations as DPV is added to the system. Finally, additional work is required to assess how extensible these results are other feeders, and to examine cases where large, ground-mount PV systems dominate. 


\section{References}

Adhikari, Sanket. 2015. “APS Solar Partner Program.” Presented at NREL, Golden, CO. October 22-23, 2015. https://www.nrel.gov/esif/assets/pdfs/highpenworkshop_adhikari.pdf.

California Public Utilities Commission. 2018. "Rule 21 Interconnection." http://www.cpuc.ca.gov/Rule21/. (retrieved March 26, 2018).

Cole, Wesley, Trieu Mai, James Richards, Paritosh Das, and Paul Donohoo-Vallett. 2017. 2017 Standard Scenarios Report: A U.S. Electricity Sector Outlook. Golden, CO: National Renewable Energy Laboratory. NREL/TP-6A20-68548. https:/www.nrel.gov/docs/fy18osti/68548.pdf.

Dagle, J.E., and D.R. Brown. 1997. Electric Power Substation Capital Costs. Richland, WA: Pacific Northwest National Laboratory. PNNL-11815. https://www.osti.gov/scitech/biblio/645480/.

Ding, Fei, Kelsey Horowitz, Barry Mather, and Bryan Palmintier. Forthcoming. "Sequential Mitigation Solutions to Enable Distributed PV Grid Integration." IEEE Power \& Energy Society (PES) General Meeting, August 5-10, 2018, Portland, Oregon.

Ding, Fei and Barry Mather. 2017. "On Distributed PV Hosting Capacity Estimation, Sensitivity Study, and Improvement." IEEE Transactions on Sustainable Energy. 8(3): 1010-1020.

Dubey, Anamika and Surya Santoso. 2017. "On Estimation and Sensitivity Analysis of Distribution Circuit's Photovoltaic Hosting Capacity." IEEE Transations on Power Systems. 32(4): 2779-2789.

EIA. 2017. Form EIA-861M (formerly EIA-826) detailed data. https://www.eia.gov/electricity/data/eia861m/.

Ebe, Falko , Basem Idlbi, Jeromie Morris, Gerd Heilscher, and Florian Meier. "Evaluation of PV Hosting Capacity of Distribuion Grids Considering a Solar Roof Potential Analysis: Comparison of Different Algorithms." In IEEE Photovoltaic Specialists Conference. 2016.

EPRI. 2012. Stochastic Analysis to Determine Feeder Hosting Capacity for Distributed Solar $P V$. Technical Update 1026640. https://www.epri.com/\#/pages/product/1026640/.

EPRI. n.d. "Simulation Tool: OpenDSS," http://smartgrid.epri.com/SimulationTool.aspx

Fu, Ran, David Feldman, Robert Margolis, Mike Woodhouse, and Kristen Ardani. 2017. U.S. Solar Photovoltaic System Cost Benchmark: Q1 2017. Golden, CO: National Renewable Energy Laboratory. NREL/TP-6A20-68925. https:/www.nrel.gov/docs/fy17osti/68925.pdf.

GTM Research and SEIA. 2017. U.S. Solar Market Insight Report, Q2 2017.

HECO. 2017. Integration Tools and Resources: Locational Value Maps. https://www.hawaiianelectric.com/clean-energy-hawaii/integration-tools-andresources/locational-value-maps 
Horowitz, Kelsey A. W., Bryan Palmintier, Barry Mather, and Paul Denholm. Forthcoming. "Distribution System Costs Associated with the Deployment of Photovoltaic Systems," Renewable and Sustainable Energy Reviews.

Lave, Matthew, Matthew J. Reno, and Robert J. Broderick. 2015. "Characterizing Local HighFrequency Solar Variability and Its Impact to Distribution Studies.” Solar Energy 118 (August): 327-337. doi:10.1016/j.solener.2015.05.028.

McConnell, Erica and Cathy Malina. "At What Price? How to Improve Interconnection Cost Certainty and Predictability.” GTM. June 12, 2017.

MTS (More than Smart). 2016. Locational Net Benefit Analysis Working Group: Webinar. October 19, 2016. http://drpwg.org/wp-content/uploads/2016/07/October-LNBA-slide-deck.pptx.

Navigant Consulting. 2016. Dynamic Load Flow Studies of Distribution Feeds in the San Joaquin Valley Region: Interim Report as of July 21, 2016. Navigant Consulting. http://drpwg.org/wp-content/uploads/2016/07/CEC_SCE-Phase-3-Interim-Report-2016-0721.pdf.

NREL (National Renewable Energy Laboratory). 2017. "Distribution Grid Integration Unit Cost Database." https://www.nrel.gov/solar/distribution-grid-integration-unit-cost-database.html. (retrieved December 2017).

Palmintier, Bryan, Robert Broderick, Barry Mather, Michael Coddington, Kyri Baker, Fei Ding, Matthew Reno, Matthew Lave, and Ashwini Bharatkumar. 2016. On the Path to SunShot: Emerging Issues and Challenges in Integrating Solar with the Distribution System. Golden, CO: National Renewable Energy Laboratory. NREL/TP-5D00-65331. http://www.nrel.gov/docs/fy16osti/65331.pdf.

Pudjianto, D. P. Djapic, J. Dragovic, and G. Strbac. 2013. Grid Integration Cost of PhotoVoltaic Power Generation" Direct Costs Analysis related to Grid Impacts of Photovoltaics. London: Imperial College London. http://www.pvparity.eu/fileadmin/PVPARITY_docs/public/PV_PARITY_D44_Grid integration _cost_of_PV_-_Final_300913.pdf.

Rylander, Matthew, Jeff Smith, and Wes Sunderman. 2016. "Streamlined Method for Determining Distribution System Hosting Capacity," IEEE Transactions on Industry Applications 52 (1), 105-111.

Rylander, Matthew, Matthew J. Reno, Jimmy E. Quiroz, Fei Ding, Huijuan Li, Robert J. Broderick, Barry Mather, and Jeff Smith. 2016. IEEE 43 ${ }^{\text {rd }}$ Photovoltaic Specialists Conference (PVSC), Portland, OR, pp. 1393-1398.

Seguin, Rich, Jeremy Woyak, David Costyk, Josh Hambrick, and Barry Mather. 2016. HighPenetration PV Integration Handbook for Distribution Engineers. Golden, CO: National Renewable Energy Laboratory. NREL/TP-5D00-63114. https://www.nrel.gov/docs/fy16osti/63114.pdf. 
Sena, Santiago S., Jimmy E. Quiroz, and Robert J. Broderick. 2014. Analysis of 100 SGIP Interconnection Studies. Albuquerque, NM: Sandia National Laboratories. SAND2014-4753. 2014. http://energy.sandia.gov/wp-content/gallery/uploads/dlm_uploads/Analysis-of-100-SGIPInterconnection-Studies.pdf.

Seuss, John, Matthew J. Reno, Robert J. Broderick, Santiago Grijalva. 2015. "Improving Distribution Network PV Hosting Capacity via Smart Inverter Reactive Power Support." IEEE Power \& Energy Society General Meeting, Denver, CO, July 26-30.

Stetz, Thomas, Markus Kraiczy, Martin Braun, and Sebastian Schmidt. 2013. "Technical and Economical Assessment of Voltage Control Strategies in Distribution Grids." Progress in Photovoltaics: Research and Applications 21(6): 1292-307. doi:10.1002/pip.

Stetz, Thomas, Frank Marten, and Martin Braun. 2013. "Improved Low Voltage Grid-Integration of Photovoltaic Systems in Germany." IEEE Transactions on Sustainable Energy 4(2): 534-542. doi:10.1109/TSTE.2012.2198925.

SunShot, U.S. Department of Energy. 2012. SunShot Vision Study. https://www.energy.gov/sites/prod/files/2014/01/f7/47927.pdf.

von Appen, Jan, Martin Braun, Thomas Stetz, Konrad Diwold, and Dominik Geibel. 2013. "Time in the Sun: The Challenge of High PV Penetration in the German Electric Grid." IEEE Power and Energy Magazine.

Western Electric Industry Leaders. Letter to "Governors, Commissioners, and Legislators." August 7, 2013. http://www.weilgroup.org/WEIL_Smart_Inverters_Letter_Aug-7-2013.pdf. 